\title{
Fabrication of Organic Shape-stabilized Phase Change Material and Its Energy Storage Applications
}

Xinpeng $\mathrm{Hu},{ }^{1,2,3} \mathrm{Hao} \mathrm{Wu},{ }^{1,2,3}$ Shuang Liu,,${ }^{1,2,3}$ Shang Gong, ${ }^{1,2,3}$ Yu Du, ${ }^{1,2,3}$ Xiaolong Li, ${ }^{1,2,3}$ Xiang $\mathrm{Lu}^{1,2,3^{*}}$ and Jinping $\mathrm{Qu}^{1,2,3,4^{*}}$

\begin{abstract}
Organic phase change materials (OPCMs) are advanced energy storage materials with the ability to storage and release thermal energy at a constant temperature. Efficient energy storage systems using shape-stabilized PCMs (SSPCMs) are promising to adjust the gap between energy supply and demand. The performances of SSPCMs are influenced by multiple factors which are necessary to be considered in the fabrication process. In this regard, we summarized the desired properties for OPCMs and SSPCMs, then we systematically discussed the fabrication methods involving supporting materials, OPCMs, and fillers. At last, we elaborated on the thermal storage applications of SSPCMs from three kinds of energy sources. This review intends to provide in-depth and constructive insights into the fabrication and energy storage applications of SSPCMs, thereby contributing to the development and application of high-performance SSPCMs.
\end{abstract}

Keywords: Organic phase change materials; Shape-stabilized phase change materials; Fabrications; Energy storage applications. Received: 01 April 2021; Revised: 23 May 2022; Accepted date: 23 May 2021.

Article type: Review article.

\section{Introduction}

Energy consumption has been booming in the past decades and is predicted to increase rapidly shortly. ${ }^{[1]}$ With the rapid exploitation and shortage of fossil energy sources, access to sustainable energy and high efficiency has been the cornerstone of both industrial development and economic growth. ${ }^{[2]}$ Numerous attention is put onto discovering new energy sources while only one-fifth of present energy comes from efficient energy conversion and storage. On

${ }^{1}$ Key Laboratory of Material Chemistry for Energy Conversion and Storage, Huazhong University of Science \& Technology, Ministry of Education, Wuhan 430074, PR China.

${ }^{2}$ Hubei Key Laboratory of Material Chemistry and Service Failure, School of Chemistry and Chemical Engineering, Huazhong University of Science \& Technology, Wuhan 430074, PR China.

${ }^{3}$ Hubei Engineering Research Center for Biomaterials and Medical Protective Materials.

${ }^{4}$ National Engineering Research Center of Novel Equipment for Polymer Processing, Key Laboratory of Polymer Processing Engineering, Ministry of Education, Guangdong Provincial Key Laboratory of Technique and Equipment for Macromolecular Advanced Manufacturing, School of Mechanical and Automotive Engineering, South China University of Technology, Guangzhou, 510641, China.

*Email: luxiang@hust.edu.cn or luxiang_1028@163.com (X. Lu), jpqu@hust.edu.cn (J. Qu) account of the adjustment of energy storage between the gap of energy utilization and supply, energy storage system especially the storage system based on thermal energy whose utilization and waste account for $90 \%$ of primary energy sources has attracted a growing amount of attention. ${ }^{[3,4]}$

Thermal energy storage consists of three main categories: sensible heat storage, latent heat storage, and thermochemical energy storage. ${ }^{[5]}$ Among these methods, phase change material (PCM)-based latent heat storage is the most promising thermal energy storage method attributing to higher energy capacity compared with sensible heat storage and stability outweighing thermochemical storage ${ }^{[6]}$ In addition, as the core working substances, PCMs are promising for its potentials in both cooling and heating with their capability to store and release thermal energy at a constant temperature. ${ }^{[7]}$ Therefore, PCMs have attracted the most attention and have been used in various practical occasions such as water heating, ${ }^{[8]}$ data center cooling, ${ }^{[9]}$ building comfort, ${ }^{[10]}$ thermal management, and ${ }^{[11]}$ energy storage. ${ }^{[12]}$ The classification of normally used PCMs is illustrated in Fig. 1, varied by the chemical composition, the PCMs are divided into classes of inorganic and organic. ${ }^{[13]}$

Inorganic PCMs compose of metal, salt, and salt hydrate which always own high volumetric latent heat and high thermal conductivity. ${ }^{[14]}$ Whereas, supercooling, as well as phase separation, severely constrain the widespread applications of inorganic PCMs which show unsatisfied 


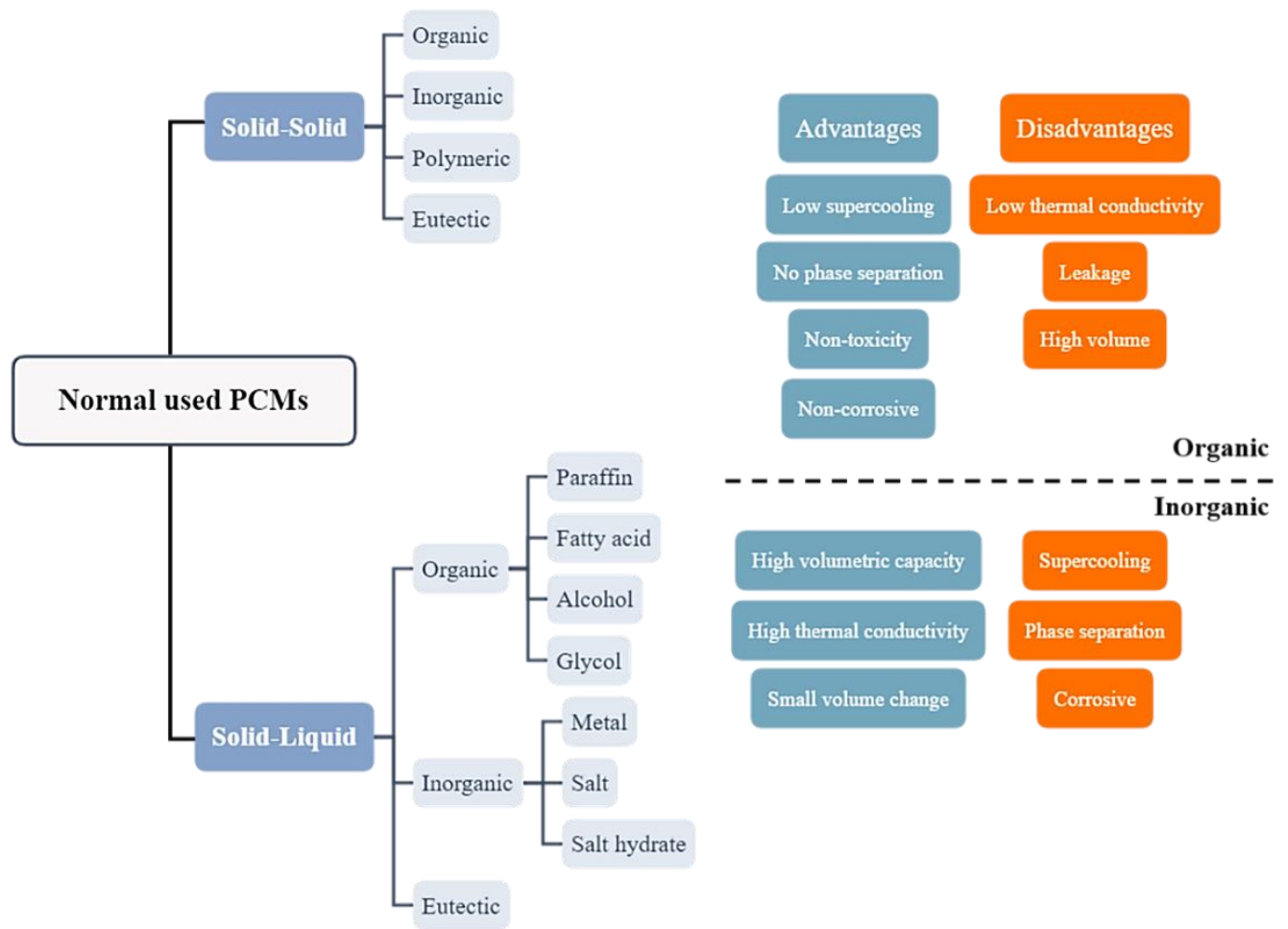

Fig. 1 Classification of normally used PCMs and corresponding characteristics.

reusability in long-term service. Conversely, organic PCMs (OPCMs) distinguish for low supercooling, ignorable phase change, nontoxicity, high energy capacity, and chemical stability, exhibiting great potential in practical implements. ${ }^{[15-}$ ${ }^{17]}$ In this regard, we will only discuss shape-stabilized PCMs (SSPCMs) based on OPCMs in this review.

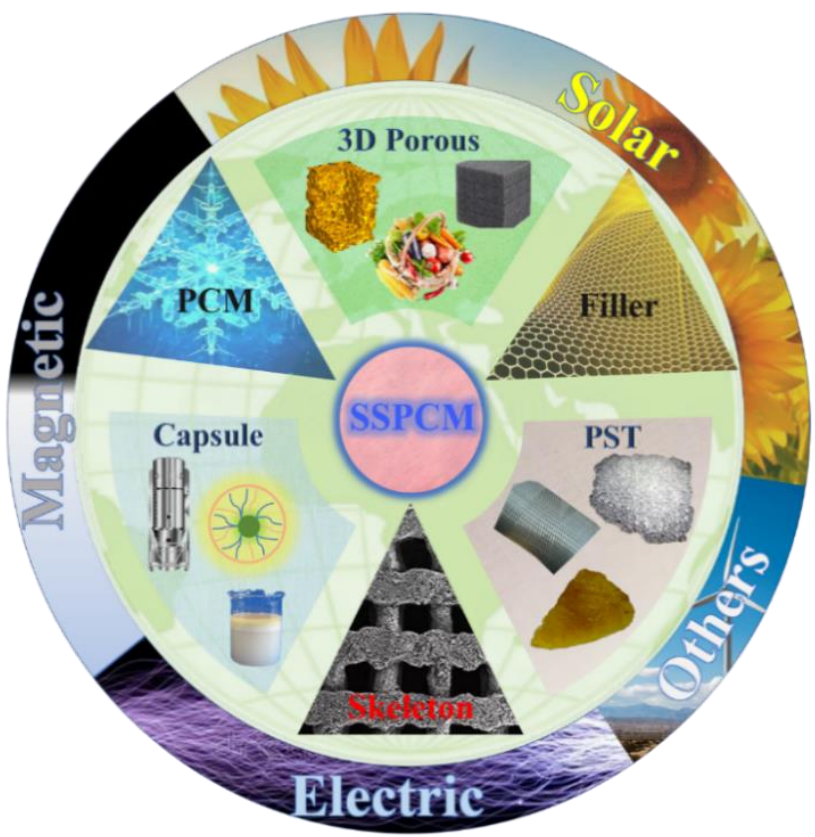

Fig. 2 The thermal energy storage of SSPCMs and influence factors.

For the SSPCMs, multiple energy forms such as electricity, magneticity and solar energy, etc. could transform into thermal energy which broadens its energy storage application (Fig. 2). ${ }^{[18]}$ Considering the parameters influencing the energy storage properties, on one hand, SSPCMs are supported by skeletons that always combine with filler to hold PCMs. On the other hand, the fabrication methods could significantly influence the properties of SSPCMs. Specifically, taking the thermal conductivity as an example, the thermal conductivity of PCM and matrix are two critical factors. Whereas, highly conductive fillers are always introduced to reinforce the thermal conductivity owing to the low thermal conductivity of SSPCMs inherent in the OPCMs. In this situation, the thermal conductivity of filler and its dispersion also make many differences to the properties of SSPCMs. Same to thermal conductivity, the leakage-proof property is mainly related to the OPCM, filler, and matrix as well as the manufacturing method, on condition, all of the aforementioned factors significantly influence the interactions between each component. ${ }^{[19]}$ Therefore, the performance of SSPCMs is determined by four factors: OPCM, skeleton, filler, and fabrication method which are necessary to be comprehensively considered.

To the best of our knowledge, there are many systematic reviews concentrating on one of the crucial parts to discuss the development of SSPCMs. Zhou et al. ${ }^{[20]}$ reviewed the application of CPCMs on energy storage, Usman and Ahmed ${ }^{[21]}$ compared the fabrication of SSPCMs based on carbon and BN, Yuan et al. ${ }^{[22]}$ summarized engineering on both the thermal conductivity enhancement and reduction of the SSPCMs, fabrication techniques ${ }^{[23]}$ and applications ${ }^{[24-26]}$ were also reviewed. However, there are few reviews considering comprehensive factors concerning the fabrication and energy 
storage of OPCMs. The aspects including the classification and choice of OPCMs, fillers fabrication methods, and energy storage applications. Thereby, we provide a critical review with comprehensive considerations from initial developments of SSPCMs to final applications in energy storage. The review aims to inspire the initial stage of developing SSPCMs with practical potential.

\section{Desirable properties of organic OPCMs and SSPCMs}

Phase change process including heat storage and release is vital to all of the applications of SSPCMs. The typical phase change process is shown in Fig. 3, as the PCMs begin to absorb heat, the temperature begins to rise from the bottom, and the peak represents sensible heat storage. When the temperature reaches melting temperature, it keeps constant for a period, corresponding to latent heat storage. Then, the temperature goes on growing rapidly, the energy storage goes back to the sensible heat storage. Once the heat supply was cut off, the temperature would experience a reversible trend to the original level. Highlighting in the figure, there are many factors influencing the heat storage process. The temperatureincreasing rate is closely related to thermal conductivity while higher thermal conductivity means quicker temperature changes. On the other hand, the isothermal process corresponds to the solid-liquid (solid-solid) phase change process, with higher latent heat, the temperature could keep constant for a longer time. Besides, the supercooling represents the gap between melting and freezing temperatures which makes much difference in the reusability of SSPCMs. Thereby, to meet the requirements of energy storage systems, the PCMs should be carefully chosen at the beginning of SSPCMs developments.

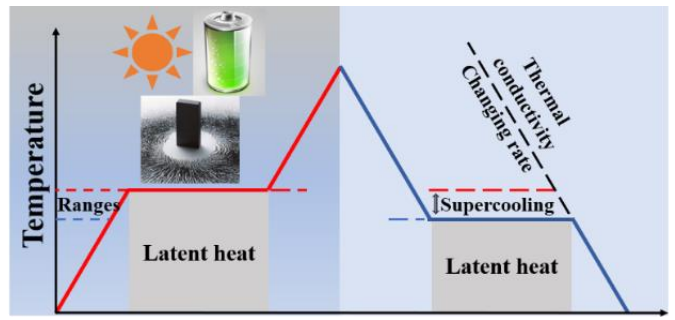

Fig. 3 Phase change process of PCM (SSPCM) and related parameters.

Several desirable properties for OPCMs and SSPCMs are summarized below and the fabrication of SSPCMs should fulfill the properties as much as possible.

In Detail, the properties of the OPCMs involve:

(a) Suitable phase change temperature, practical utilization temperature must locate within the phase change temperature, otherwise the phase change process hardly takes effect.

(b) High latent heat of transition, the value influences the volume or weight of whole SSPCMs which determines the application space. The high-capacity, small-volume, and lightweight SSPCMs are preferred.

(c) Narrow supercooling, narrow supercooling means a uniform melting and freezing process that benefits the reusability and precise thermal management property of SSPCM.

(d) Compatibility with container materials, the OPCM is held by the supporting materials or container materials, thus compatibility is essential to avoid phase segregation, leakage, and deformation.

(e) Low vapor pressure, evaporation was inevitable in the practical application in which low vapor pressure both reduces the weight loss of OPCM and the risk of vapor leakage.

(f) Low price, in large-scale utilization, low price facilitates the widespread of the corresponding OPCM.

For SSPCMs, the properties include:

(g) Leakage-proof properties, the OPCMs melt into the liquid in a phase change process which would lead to leakage and corrosion of the container, deteriorating the performance of SSPCMs.

(h) High thermal conductivity, thermal conductivity matters much in energy diffusion which is related to the energy charging rate.

(j) Chemical stability, the resistance to the variable environmental is preferred.

(k) Reusability, the properties of SSPCMs alter easily in longterm service, therefore the reusability makes much difference in practical applications.

(1) Non-toxicity, fire hazard, or flammability.

Compared to the ideal properties of OPCMs and SSPCMs, plenty of features of SSPCMs are inherent in OPCMs. Despite the importance of PCMs on the fabrications of SSPCMs, there are still some other factors influencing the properties of SSPCMs such as the interaction between components and fabrication methods, and the relationship between the properties of SSPCMs and OPCMs is complicated. To acquire the desire properties of SSPCMs, all the factors need to be rationally taken into account. Taking high thermal conductivity as an example, the enhancement is not always ideal due to high thermal interfacial resistance. Some works reported launching chemical interaction to increase the contact area which could significantly improve the thermal conductivity. However, chemical reactions always involve pollution, toxic chemicals, and higher cost which are not proper in some practical occasions. Higher thermal conductivity always accompanies other costs. In a word, the implementation of one performance may affect another, the design of SSPCMs always faces a trade-off and is a systematic work that needs to be considered according to actual requirements rather than obey the unified specification.

\section{Classification and properties of OPCMs}

In the long history of PCM utilizations, the four main divisions of OPCMs are paraffin wax (PW), fatty acid, alcohol, and polyalcohol.

PW, as a byproduct of crude oil, has been applied on varying occasions owing to the low cost and abundant supply. ${ }^{[27,28]}$ Its application lasts a long history and has been 
Table 1. Thermophysical properties of paraffin with carbon number (15-44). ${ }^{[29}$

\begin{tabular}{ccccccc}
\hline $\begin{array}{c}\text { Carbon } \\
\text { Number }\end{array}$ & Alkane & $\begin{array}{c}\mathrm{MM} \\
(\mathrm{g} / \mathrm{mol})\end{array}$ & $\mathrm{T}_{\mathrm{tr}}\left({ }^{\circ} \mathrm{C}\right)$ & $\Delta \mathrm{H}_{\text {tr }}(\mathrm{J} / \mathrm{g})$ & $\mathrm{T}_{\mathrm{m}}\left({ }^{\circ} \mathrm{C}\right)$ & $\Delta \mathrm{H}_{\mathrm{m}}(\mathrm{J} / \mathrm{g})$ \\
\hline 15 & Pentadecane & 212.42 & 2.3 & 43 & 9.9 & 163 \\
17 & Heptadecane & 240.47 & 10.6 & 46 & 21.7 & 167 \\
19 & Nonadecane & 268.53 & 22.3 & 51 & 31.7 & 170 \\
21 & Heneicosane & 296.58 & 32.4 & 55 & 40.0 & 161 \\
22 & Docosane & 310.61 & 40.0 & 93 & 43.6 & 157 \\
23 & Tricosane & 324.63 & 42.2 & 67 & 47.2 & 164 \\
24 & Tetracosane & 338.66 & 47.5 & 94 & 50.4 & 161 \\
25 & Pentacosane & 352.69 & 47.1 & 76 & 53.1 & 162 \\
26 & Hexacosane & 366.71 & 52.8 & 92 & 56.0 & 164 \\
27 & Heptacosane & 380.74 & 53.1 & 70 & 58.5 & 161 \\
28 & Octacosane & 394.77 & 57.3 & 89 & 61.0 & 165 \\
30 & Triacontane & 422.82 & 59.0 & 88 & 65.0 & 162 \\
32 & Dotriacosane & 450.88 & 64.0 & 91 & 69.3 & 168 \\
33 & Tritriacontane & 464.90 & 67.8 & 67 & 71.1 & 171 \\
34 & Tetratriacosane & 478.93 & 69.0 & 100 & 72.4 & 166 \\
35 & Pentatriacontane & 492.96 & 72.0 & 83 & 74.6 & 175 \\
36 & Hexatriacosane & 506.98 & 73.8 & 61 & 75.8 & 173 \\
\hline
\end{tabular}

used in the discovery of the neutron in 1932 by Chadwick. ${ }^{[30]}$ length of the alkanes chain, thereby, properties like melting Several investigations have been conducted to measure the point could be tuned by controlling the average number of thermal properties of linear alkanes since the 1930s (Table 1). carbon atoms. However, the nature of the mixture makes it $\mathrm{PW}$ is a mixture of alkanes with different numbers of carbon difficult to determine molecule weight which is associated atoms whose chemical formula is $\mathrm{CH}_{3}\left(\mathrm{CH}_{2}\right)_{n} \mathrm{CH}_{3}$, and $\mathrm{n}$ with thermal properties. Generally, the $\mathrm{H}_{m}(120$ to $200 \mathrm{~J} / \mathrm{g})$ normally ranges from 15 to 50 to ensure the solid state at room and $\mathrm{T}_{m}\left(12\right.$ to $\left.200{ }^{\circ} \mathrm{C}\right)$ increases by the carbon atoms. temperature. The physical properties of PW differ with the

Table 2. Thermophysical properties of fatty acids are normally used as PCMs. ${ }^{[31]}$

\begin{tabular}{|c|c|c|c|c|c|c|c|}
\hline & Acid & $\begin{array}{l}\text { Chemical } \\
\text { Formula } \\
\end{array}$ & $\begin{array}{c}\mathrm{MM} \\
(\mathrm{g} / \mathrm{mol}) \\
\end{array}$ & $\operatorname{Ttr}\left({ }^{\circ} \mathrm{C}\right)$ & $\begin{array}{l}\Delta \mathrm{Htr} \\
(\mathrm{J} / \mathrm{g}) \\
\end{array}$ & $\operatorname{Tm}\left({ }^{\circ} \mathrm{C}\right)$ & $\begin{array}{l}\Delta \mathrm{Hm} \\
(\mathrm{J} / \mathrm{g}) \\
\end{array}$ \\
\hline \multirow{14}{*}{$\begin{array}{l}\text { Fatty } \\
\text { acid }\end{array}$} & Enanthic & $\mathrm{C}_{7} \mathrm{H}_{14} \mathrm{O}_{2}$ & 130.18 & -48.4 & 16 & -7.4 & 107 \\
\hline & Caprilic & $\mathrm{C}_{8} \mathrm{H}_{16} \mathrm{O}_{2}$ & 144.21 & & & 16.5 & 148 \\
\hline & Pelargonic & $\mathrm{C}_{9} \mathrm{H}_{18} \mathrm{O}_{2}$ & 156.24 & 10.2 & 34 & 12.3 & 127 \\
\hline & Capric & $\mathrm{C}_{10} \mathrm{H}_{20} \mathrm{O}_{2}$ & 172.26 & & & 30.8 & 159 \\
\hline & Undecylic & $\mathrm{C}_{11} \mathrm{H}_{22} \mathrm{O}_{2}$ & 186.29 & 17.1 & 47 & 28.4 & 139 \\
\hline & Lauric & $\mathrm{C}_{12} \mathrm{H}_{24} \mathrm{O}_{2}$ & 200.32 & & & 42.8 & 191 \\
\hline & Tridecylic & $\mathrm{C}_{13} \mathrm{H}_{26} \mathrm{O}_{2}$ & 214.34 & 33.9 & 41 & 41.8 & 157 \\
\hline & Myristic & $\mathrm{C}_{14} \mathrm{H}_{28} \mathrm{O}_{2}$ & 228.37 & & & 52.8 & 194 \\
\hline & Pentadecylic & $\mathrm{C}_{15} \mathrm{H}_{30} \mathrm{O}_{2}$ & 242.4 & & & 52.5 & 165 \\
\hline & Palmitic & $\mathrm{C}_{16} \mathrm{H}_{32} \mathrm{O}_{2}$ & 256.43 & & & 62.4 & 204 \\
\hline & Heptadecylic & $\mathrm{C}_{17} \mathrm{H}_{34} \mathrm{O}_{2}$ & 270.45 & 56 & 27 & 62.8 & 193 \\
\hline & Stearic & $\mathrm{C}_{18} \mathrm{H}_{36} \mathrm{O}_{2}$ & 284.48 & & & 69 & 214 \\
\hline & Nonadecylic & $\mathrm{C}_{19} \mathrm{H}_{38} \mathrm{O}_{2}$ & 298.5 & 64.8 & 31 & 68 & 193 \\
\hline & Arachic & $\mathrm{C}_{20} \mathrm{H}_{40} \mathrm{O}_{2}$ & 312.53 & & & 75 & 227 \\
\hline
\end{tabular}


Table 3. Thermophysical properties of alcohols normally used as PCMs. ${ }^{[29]}$

\begin{tabular}{|c|c|c|c|c|c|c|c|}
\hline & Alcohol & $\begin{array}{c}\text { Chemical } \\
\text { formula }\end{array}$ & $\begin{array}{c}\mathrm{MM} \\
(\mathrm{g} / \mathrm{mol})\end{array}$ & $\begin{array}{l}\text { Ttr } \\
\left({ }^{\circ} \mathrm{C}\right)\end{array}$ & $\begin{array}{l}\Delta \mathrm{Htr} \\
(\mathrm{J} / \mathrm{g})\end{array}$ & $\operatorname{Tm}\left({ }^{\circ} \mathrm{C}\right)$ & $\begin{array}{r}\Delta \mathrm{Hm} \\
(\mathrm{J} / \mathrm{g})\end{array}$ \\
\hline \multirow{8}{*}{ Alcohol } & Dodecanol & $\mathrm{C}_{12} \mathrm{H}_{25} \mathrm{OH}$ & 186.34 & & & 24.1 & 216 \\
\hline & Tridecanol & $\mathrm{C}_{13} \mathrm{H}_{27} \mathrm{OH}$ & 200.36 & 21.5 & & 31.6 & 223 \\
\hline & Tetradecanol & $\mathrm{C}_{14} \mathrm{H}_{29} \mathrm{OH}$ & 214.39 & & & 37.8 & 231 \\
\hline & Hexadecanol & $\mathrm{C}_{16} \mathrm{H}_{33} \mathrm{OH}$ & 242.45 & & & 49.1 & 238 \\
\hline & Octadecanol & $\mathrm{C}_{18} \mathrm{H}_{37} \mathrm{OH}$ & 270.5 & 55.2 & & 57.8 & 246 \\
\hline & Nonadecanol & $\mathrm{C}_{19} \mathrm{H}_{39} \mathrm{OH}$ & 284.53 & 55.5 & & 61.1 & 255 \\
\hline & Eicosanol & $\mathrm{C}_{20} \mathrm{H}_{41} \mathrm{OH}$ & 298.55 & 56.5 & & 64.5 & 247 \\
\hline & Docosanol & $\mathrm{C}_{22} \mathrm{H}_{43} \mathrm{OH}$ & 326.61 & 66.6 & & 70.4 & 263 \\
\hline
\end{tabular}

A fatty acid is mainly derived from biomass like vegetables and animal oil, the renewable nature ensures an abundant source. The molecular formula of fatty acid is $\mathrm{CH}_{3}\left(\mathrm{CH}_{2}\right)_{\mathrm{n}} \mathrm{COOH}$ whose main body is an alkane group and ends up with a - $\mathrm{COOH}$ group (Table 2).

Owing to its smaller temperature swing and potential to combine with other materials, it becomes an important group of materials in thermal energy storage. The SSPCMs based on the fatty acid are suitable for medium-temperature applications which are always accompanied by a high phase change entropy ${ }^{[32]}$ However, the bad odor and corrosivity are the main aspects hindering the applications of fatty acid, thereby sometimes fatty acid derivatives like ethers are served as alternatives.

Alcohol has the same backbone as the PW. The alcohols used as OPCMs are mainly with carbon numbers beyond 12 which is a solid state at room temperature. Different from PW, the end group - $\mathrm{OH}$ of alcohol enables it well dissolve in hydrophilic substances. Alcohol could be transformed from biomass and chemical with abundant supply, it also possesses comparable properties to PW and fatty acids such as good chemical and thermal stability, melting congruency, nontoxicity, etc. The normally used alcohol and its corresponding properties are summarized in Table 3.
Polyalcohol used as OPCMs is referred to the polyalcohol in solid condition at room temperature with a molecule weight beyond 600. The chemical formula of polyalcohol denotes $\mathrm{HO}\left(\mathrm{CH}_{2} \mathrm{CH}_{2} \mathrm{O}\right)_{n} \mathrm{H}$. Several normal polyalcohols are illustrated in Table 4. Worth mentioning, despite the general advantages inherent in OPCMs, polyalcohol distinguishes for its high latent energy capacity which approaches $300 \mathrm{~J} / \mathrm{g}$, remarkably higher than fatty acid and PW.

Compared to PW, fatty acid, alcohol, and PEG, the obvious difference comes from latent heat. As shown in Fig. 4, the latent heat of fatty acid and alcohol shows an increase trend along with mole molecular weight while the latent heat and mole molecular weight of PW show little relationship. In addition, the latent heat of alcohols is relatively higher than fatty acid and PW. As for the PEG, the latent heat is firstly increased with mole molecular weight $(<10000 \mathrm{~g} / \mathrm{mol})$. With the mole molecular further, increasing, the latent heat shows a reduction. Overall, the latent heat of alcohol is relatively higher while that of PW shows a small swing.

Another difference between the OPCMs comes from the chemical structure especially the end group, the PW has an alkyl end group that is inert, it hardly reacts with another component, thus the interactions between PW and matrices are mainly physical. For the fatty acid and alcohol having the

Table 4. Thermophysical properties of polyalcohols normally used as PCMs. ${ }^{[33]}$

\begin{tabular}{cccccc}
\hline $\mathrm{MM}(\mathrm{g} / \mathrm{mol})$ & $\Delta \mathrm{Htr}(\mathrm{J} / \mathrm{g})$ & $\mathrm{T}_{\operatorname{tr}}\left({ }^{\circ} \mathrm{C}\right)$ & $\Delta \mathrm{H}_{\mathrm{m}}(\mathrm{J} / \mathrm{g})$ & $\mathrm{T}_{\mathrm{m}}\left({ }^{\circ} \mathrm{C}\right)$ \\
\hline 400 & 85.0 & -24 & 91.4 & 3.2 \\
600 & 116.1 & 6.9 & 121.1 & 18.5 \\
$\mathrm{PEG}$ & 147.7 & 27.5 & 156.1 & 36.9 \\
& 1000 & 139.7 & 26.2 & 154.1 & 52.5 \\
& 2000 & 159.0 & 29.0 & 174.1 & 56.6 \\
& 3400 & 152.9 & 32.3 & 164.9 & 62.8 \\
& 4000 & 168.7 & 34.2 & 172.4 & 62.2 \\
& 5000 & 177.9 & 39.6 & 181.5 & 59.6 \\
& 6000 & 178.0 & 48.9 & 189.5 & 63.0 \\
& 8000 & 201.1 & 46.7 & 197.2 & 67.0 \\
& 10000 & 154.2 & 49.4 & 176.2 & 61.2 \\
\hline
\end{tabular}




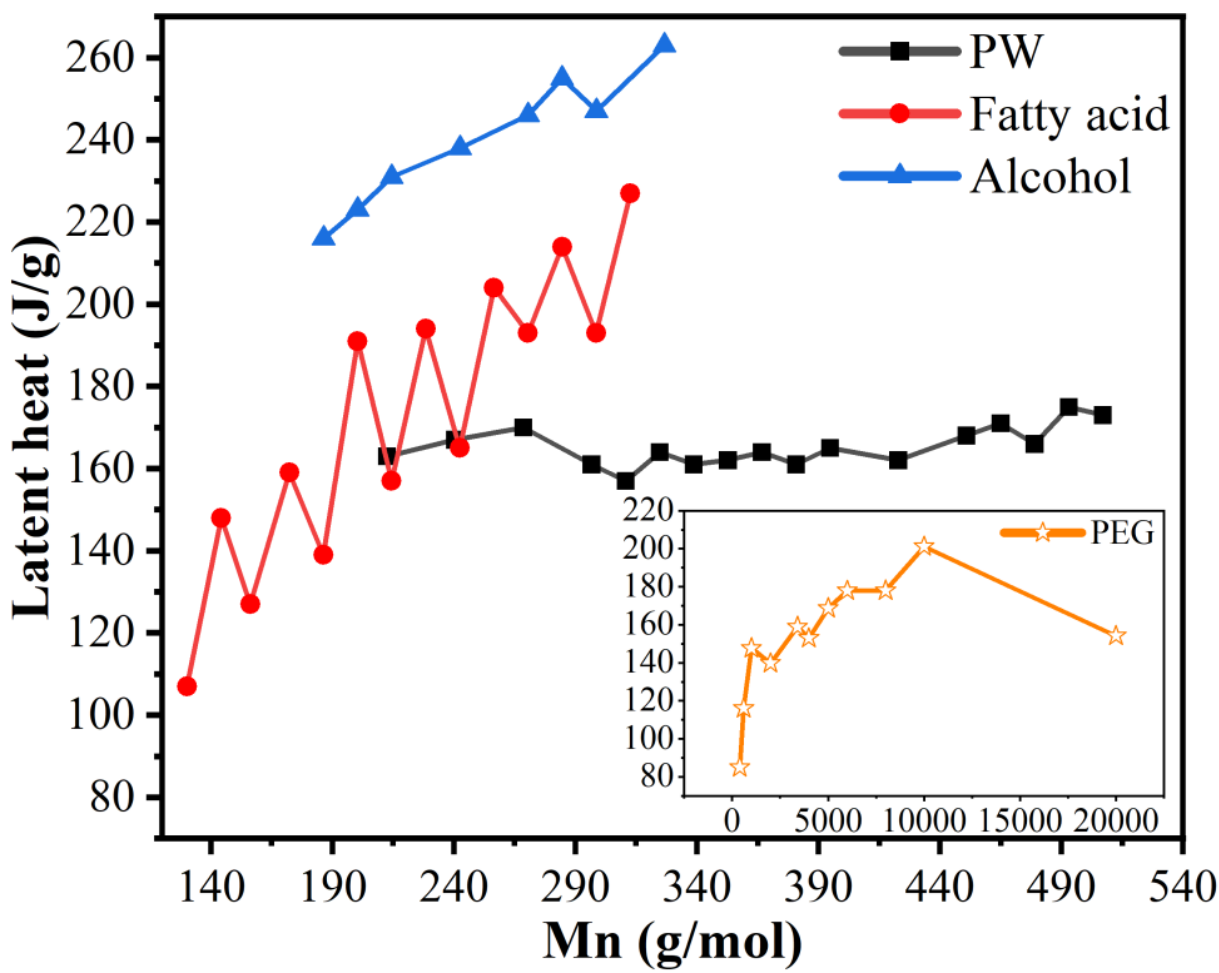

Fig. 4 The relationship between latent heat and mole molecular weight of PW, fatty acid, alcohol, and PEG.

same backbone as the $\mathrm{PW}$, the $-\mathrm{COOH}$ and $-\mathrm{OH}$ end group could form covalent bonds with matrices and fillers, the interactions strengthen the connections between PCMs and matrices which increase the loading rate of PCMs in the fabrication of SSPCMs. For example, fatty acid could react with various alcohols to conduct esterification reactions, otherwise, it may corrode the supporting materials. Moreover, the $-\mathrm{COOH}$ and $-\mathrm{OH}$ could assist the PCMs to attach to the matrices with hydrogen bonds to shape and stabilize the composite PCMs. It is worth mentioning that the $-\mathrm{OH}$ is hydrophilic, it could dissolve in water which would much influence the performance of SSPCM in a water-soluble environment. On different occasions, varied OPCMs could be chosen with different requirements.

There are other OPCMs as working substances in developing SSPCMs which own remarkable advantages. Chen et $a l^{[34]}$ first exploited fatty amines as working substances to fabricate SSPCMs. The fatty amines exhibited exceptionally high latent heat ranging from 261 to $306 \mathrm{~J} / \mathrm{g}$. Furthermore, the graphene aerogel was developed to absorb fatty amine to fabricate SSPCMs. ${ }^{[35]}$ As expected, the GA could absorb high content of fatty amine which leads to a high energy capacity of SSPCMs.

On the other hand, in the merit of the nature of the blend to combine the properties of the composition, eutectic OPCMs distinguish for controlling phase change temperature and less phase separation compared with pure substances. ${ }^{[30]}$ Through the self-polymerization method, Wang and coauthors ${ }^{[36]}$ selected capric acid (CA), lauric acid (LA), myristic acid (MA), and stearic acid (SA) to prepare binary fatty acid eutectic for the sake of decreasing the phase change temperature. CA-LA, CA-MA, CA-SA, and LA-MA binary eutectics acting as the heat-absorbing materials and PMMA serving as the supporting material were compounded in a ratio of 50/50 wt.\%. Although the phase change entropy of the SSPCMs is relatively low whose max value was only 80.75 $\mathrm{J} / \mathrm{g}$, the phase change temperature varying from 21 to $35^{\circ} \mathrm{C}$ is extremely suitable for building energy conservation.

The polymers could be also used as phase change materials. The PLA blending with high-density polyethylene (HDPE) PCM shows great potential in solar energy storage. ${ }^{[37]}$ With a weight ratio of 50:50, the latent heat for the PLA50/HDPE50 blend during the melting and freezing process is $100.1 \mathrm{~J} / \mathrm{g}$ and $97.6 \mathrm{~J} / \mathrm{g}$, respectively, accompanied by the relative enthalpy efficiency reaching as high as $104.2 \%$.

With much attention concentrating on PCMs, new PCMs with great potential are constantly emerging. Matuszek et al. ${ }^{[38}$ presented a group of organic salt PCMs based on pyrazolium cation (Pzy), the PCMs own working temperature ranging between 100 to $168^{\circ} \mathrm{C}$ and latent heat ranging from 40 to 160 $\mathrm{J} / \mathrm{g}$. Among the Pzy-based PCMs, the $[\mathrm{Pzy}]\left[\mathrm{CH}_{3} \mathrm{SO}_{3}\right]$ is the most potential candidate for thermal energy storage with a melting temperature of $168{ }^{\circ} \mathrm{C}$ and latent heat of $160 \mathrm{~J} / \mathrm{g}$. In addition, organic salts are famous for highly chemical and physical stability, nonflammability, and excellent heat transfer properties. The $[\mathrm{Pzy}]\left[\mathrm{CH}_{3} \mathrm{SO}_{3}\right]$ salt could resist the temperature as high as $275^{\circ} \mathrm{C}$ without pressure changes and long-term thermal cycling tests to keep it stable. Moreover, the costs between [Pzy] $\left[\mathrm{CH}_{3} \mathrm{SO}_{3}\right]$ and commercial PCMs (paraffin and salty hydrates) were compared. The Pzy-based PCMs were concluded to be inexpensive candidates to store energy. Overall, the work revealed a new kind of material 
showing great potential in energy storage applications and provided some new insight into fabricating functional SSPCMs.

With more requirements put on the PCMs, the further discovery of ideal OPCMs are essential in variable applications.

\section{Fabrication strategies for organic SSPCMs}

Despite the considerate advantages of OPCMs, there are still two main parameters hindering their utilization: a) leakage, and b) low conductivity. Therefore, multiple methods have been developed to get rid of these drawbacks. ${ }^{[39]}$ Porous material absorption, encapsulation, and polymer shaping technology (PST) are the three main methods to shape and stabilize composite PCMs to avoid leakage. As for the low thermal conductivity inherent in OPCMs, the efficient approach is to introduce the matrix or filler with high conductivity, both of the former aspects are closely related to the fabrication process of SSPCMs, thus it is necessary to depict the fabrication methods below.

\subsection{Three-dimensional (3D) material absorption}

To counter the leakage and improve shape stability as well as absorption rate, materials with a 3D structure such as porous foam, and aerogel are ideal candidates. On a hand, 3D structures are beneficial to stabilize the shape of composite PCMs with capillary forces, surface tension as well as hydrogen bonding, and Van der Waal's force which enables the porous and 3D supporting materials to hold the PCMs steadily. On the other hand, the high porosity and light weight increase the weight proportion of PCMs in SSPCMs, resulting in high latent heat of SSPCMs. ${ }^{[40]}$ Besides, the 3D structures provide abundant space and sites for modification and interaction which could improve comprehensive properties of SSPCMs like thermal and electric conductivity. Thereby, various kinds of $3 \mathrm{D}$ materials have been used to fabricate the SSPCMs.

\subsubsection{Metal and derivatives Metal}

Metal is well known for its high electrical and thermal conductivity which are attractive in the fabrication of functional SSPCMs. However, high density and cost hinder the adoption of the metal matrix into SSPCMs. To get rid of the drawbacks, porous metal foam and 3D light-weight metal networks are introduced to fabricate SSPCMs.

Zheng et al. ${ }^{[41]}$ successfully fabricated a copper foam/PW SSPCM and a visible device was built to investigate the melting behavior of PW with and without copper foam. The copper foam was proved to be able to shape stabilized PW and shorten the melting time of PW. Besides, the heating position of SSPCM was reported to be of great significance on the melting rate as well as temperature difference.

Using a vacuum impregnation method, Xiao et al. ${ }^{[42]}$ developed cooper foam/PW SSPCM and nickel foam/PW SSPCM, the impregnation method obtained an absorption of
PW ranging from $96.0 \mathrm{wt} . \%$ to $98.6 \mathrm{wt} . \%$. Besides, the thermal conductivity characterization showed that the thermal conductivity of the nickel foam/PW SSPCMs is nearly three times larger than that of pure PW, while that of the copper foam/PW SSPCMs is nearly 15 times larger. With such huge thermal conductivity enhancements, the phase change temperatures of both SSPCMs only experience slight shifts, demonstrating great potential in thermal management.

In Pan's work, metal networks constructed by cutting copper fiber were used to absorb PW to dissipate the heat produced by lithium-ion batteries. ${ }^{[43]}$ Based on solid-phase sintering technology, the cutting copper fiber with different weights is assembled into rigid skeletons to fabricate SSPCMs Interestingly, the manufactured cooper fiber skeleton obtained a higher PW absorption rate (71.9 wt.\%) than that of cooper foam (71.4 wt.\%). Moreover, in four types of heat dissipation methods (natural wind cooling, filled with pure PW, copper foam/PW, and copper fiber/PW), the results showed that SSPCM can effectively dissipate the heat released by working battery, achieving about $50 \%$ temperature decrease compared with natural wind cooling while the maximum temperature was kept below $60{ }^{\circ} \mathrm{C}$. Overall, the heat transfer in the battery module was much improved and the temperature difference was within $2{ }^{\circ} \mathrm{C}$ with the assistance of SSPCM, ensuring the long service of the battery module.

3D Aluminum honeycomb ${ }^{[44]}$ was also employed to enhance the thermal conductivity and mechanical properties of HDPE/EG/PW SSPCM where carbon fiber was added as a heat-conductive additive. The SSPCM acquired an ultrahigh thermal conductivity $(5.723 \mathrm{~W} / \mathrm{m} \mathrm{K})$. Simultaneously, the aluminum skeleton endowed the SSPCM with enhanced thermal conduction and heat dissipation capability, exhibiting improved battery thermal management.

As reviewed above, the cooper skeletons are most widely used in the fabrication of SSPCMs. The first reason is the excellent thermal and electrical properties with low cost, the other reason is the remarkable chemical stability and mechanical properties which are suitable for practical applications.

\section{Metal derivatives}

Other than the conventional metal systems, serving special functions such as fluorescent, magnetic, antibacterial, and electrically conductive functions, hybrid metal, and metal derivatives were also introduced to fulfill the requirements.

By particle-stabilized emulsion, a well-defined porous $\mathrm{TiO}_{2}$ foam was developed with a carbon layer which shows a 62 vol.\% PW absorption. ${ }^{[45]}$ Assisted by continuous structure, the thermal conductivity increased from $0.302 \mathrm{~W} / \mathrm{m} \mathrm{K}$ to 1.059 $\mathrm{W} / \mathrm{m} \mathrm{K}$ which showed reinforced thermal energy diffusion. In other systems, the $\mathrm{TiO}_{2}$ could also be used as thermoregulatory enzyme carriers with $\mathrm{Fe}_{3} \mathrm{O}_{4}{ }^{[46]}$ as well as dye-sensitized solar cells with Ag nanoparticles. ${ }^{[47]}$ The dope of Ag could also make SSPCM acquire catalytic properties. ${ }^{[48]}$ Zhu et al. ${ }^{[49]}$ employed ZnMgAl-mixed metal oxides (MMO) matrix to impregnate 
PEG, the PEG/MMO SSPCMs with a PEG content of $65 \mathrm{wt} \%$ acquired excellent shape stability and sufficient phase change enthalpy. Besides, the SSPCM exhibits considerate temperature regulation and aging resistance to UV light, exhibiting the potential of SSPCM novel applications.

Metal-organic framework (MOF), as an important porous material taking advantage of high porosity and surface area, was also used as a supporting material to absorb OPCMs. ${ }^{[50]}$ Luan et al. ${ }^{[51]}$ employed MOF as a matrix to absorb fatty acid, and the resulting SSPCMs exhibited SA absorption rate and latent heat as high as $80 \mathrm{wt} . \%$ and $147.3 \mathrm{~J} / \mathrm{g}$, respectively. Shown as in Fig. 5, the MOFs possess plenty of pores that are capable of absorbing PCMs. With the impregnation process, the MOF was filled with SA resulting in high absorption rates. Besides, after being grafted with the $-\mathrm{NH}_{2}$ group, the $\mathrm{SA} @ \mathrm{MOF}-\mathrm{NH}_{2} \quad$ SSPCM obtained remarkable thermal stability and durability. Coupled with excellent reusability, the MOF-based displayed great potential in energy-relevant implements.

Except for the advantages of metal and derivatives, the performances of metal/PCM SSPCMs could also be tuned by designing the shape and geometry of the metal structure. ${ }^{[52,53]}$ Coupled with the multiple functions of the metal matrix, the metal-based SSPCMs promise great potential in manufacturing advanced materials.

\subsubsection{Carbon materials}

For non-metal matrix, carbon materials were successfully employed to be supporting materials. Compared with metal matrix, the carbon materials are light-weight and the pores of $3 \mathrm{D}$ porous carbon are smaller which means a stronger ability to hold PCMs without leakage. Besides, carbon materials are compatible with a wide range of materials and theoretically have high electrical and thermal conductivity. ${ }^{[54-56]}$ Above promising feature highlights the importance of carbon materials in the fabrication of SSPCMs. Herein, carbon materials (EG, graphene, and CNT) are the hot points and much effort has been applied to combining carbon materials with the manufacture of SSPCMs.

\section{Expanded graphite (EG)}

Graphite is a kind of layered structure material which are bonded with van der Waals force between layers. Obtained from natural graphite flakes by high-temperature puffing. EG, which promises high thermal and electrical conductivity, is a loose and porous worm-structure material. In this regard, it is a highly efficient supporting skeleton to produce SSPCMs at a low cost.

Li et al. ${ }^{[57]}$ prepared an n-eicosane (C20)-based SSPCM with EG supporting material via a vacuum impregnation method to counter the low conductivity, the composite consisted of $86.47 \% \mathrm{C} 20$ and exhibited a high conductivity (3.56 $\mathrm{W} \mathrm{m}^{-1} \mathrm{~K}^{-1}$ ) with 15 wt.\% EG. Additionally, it shows considerate thermal energy storage ability as well as high electro-to-heat storage efficiency $(65.7 \%)$ under the voltage of $2.1 \mathrm{~V}$, revealing its possible application in both electro-tothermal conversion and thermal energy storage. With a similar EG/PW system ${ }^{[58]}$, a new 3D EG block-based SSPCM has been developed which has also extraordinarily large thermal conductivity of $15.6 \mathrm{~W} / \mathrm{m} \mathrm{K}$, much higher than previously reported EG-based PCMs and other carbon materials-based PCMs. EG shows sufficient potential in fabricating SSPCMs with high performances.

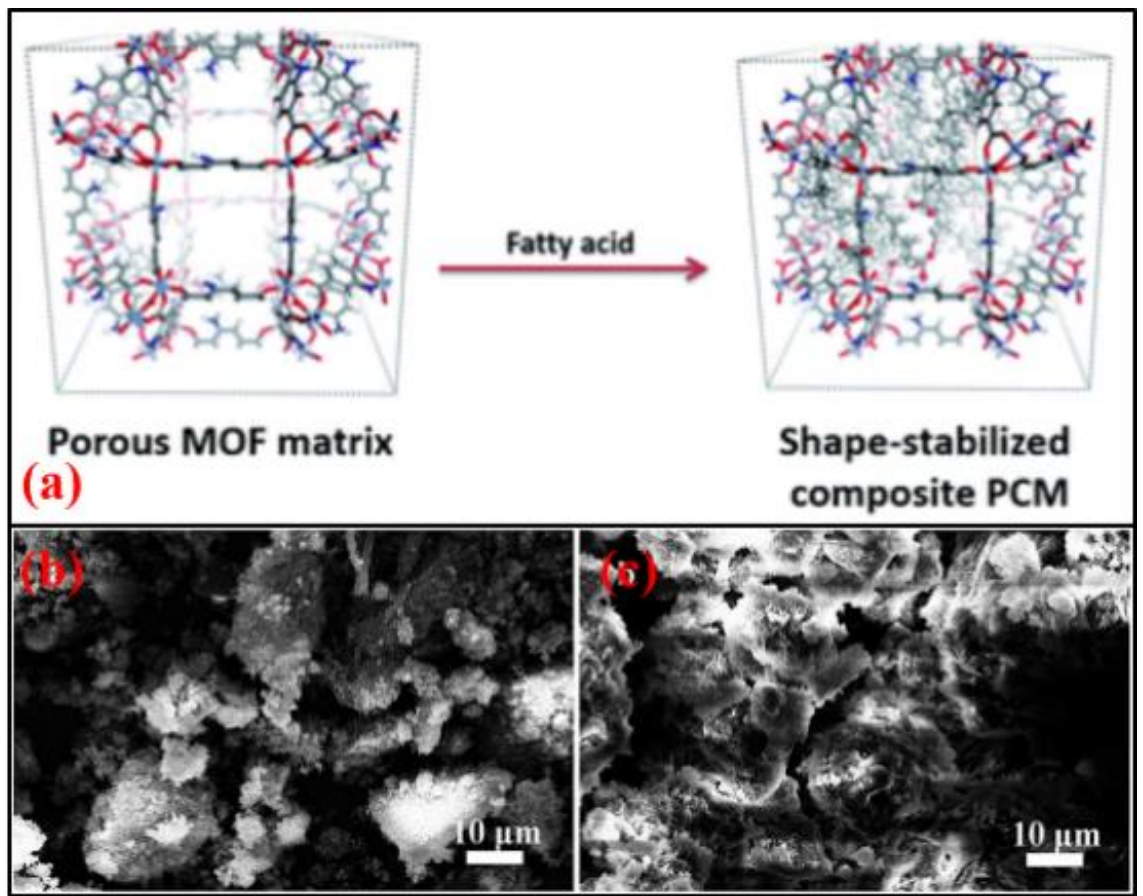

Fig. 5 (a) Schematic illustration to incorporate fatty acid PCM into the micropores of the MOF support. (b) The SEM image of MOF$\mathrm{NH}_{2}$; (c) The SEM image of SSPCMs with 70 wt.\% SA loading. (Reproduced with permission from [51], Copyright 2021 RSC). 
Lin et al. ${ }^{[59]}$ fabricated an EG (20 wt.\%)/PW SSPCM which possessed a low electrical resistance and a remarkable $960 \%$ thermal conductivity enhanced improvement compared with pure PW. The EG network served as both thermal and electric conductive pathways, novelly exhibiting full-temperature thermal management in which the battery module could be heated with joule heat and cooled with heat storage in cold and hot conditions, respectively. The temperature of the battery module could be controlled between $-40{ }^{\circ} \mathrm{C}$ to $55{ }^{\circ} \mathrm{C}$ in the whole process, extending the single-direction thermal management property of SSPCMs.

Intended for tankless solar water heaters, through a vacuum filtering method, different contents ( 2 wt.\%, 6 wt.\%, $10 \mathrm{wt} . \%$ ) of EG serve as supporting materials to absorb stearic acid. The EG/SA composites showed a latent heat beyond 160 $\mathrm{J} / \mathrm{g}$ and thermal conductivity was enhanced by 9.6 folds compared to pristine SA. Estimated by a compact solar water heater, the energy diffusion of the EG/SA was significantly enhanced in which the melting time of EG/SA was shortened by $63.3 \%$ to SA, suggesting great potential in the solar water heater systems.

Most works related to the EG-based SSPCMs hardly tune the arrangement of EG, the thermal conductivity enhancements are mainly inherited from the nature of EG. Wu et al. ${ }^{[60]}$ innovatively developed a series of highly thermally conductive SSPCM based on graphite sheets by compressioninduced construction of large-size oriented graphite sheets (Fig. 6). The resulting graphite sheets are bridged with each other and construct a continuous conductive pathway with a low junction thermal resistance. Consequently, the SSPCM acquired extremely high thermal conductivity ranging in 4.4$35.0 \mathrm{~W} / \mathrm{m} \mathrm{K}$ with graphite loadings less than $40.0 \mathrm{wt} . \%$.

\section{Carbon nanotubes (CNTs)}

CNTs are a kind of lightweight one-dimensional material with a high specific surface area, it also distinguishes themselves for ultrahigh thermal and electrical conductivity, thereby it is always used as enhancing addictive to improve the

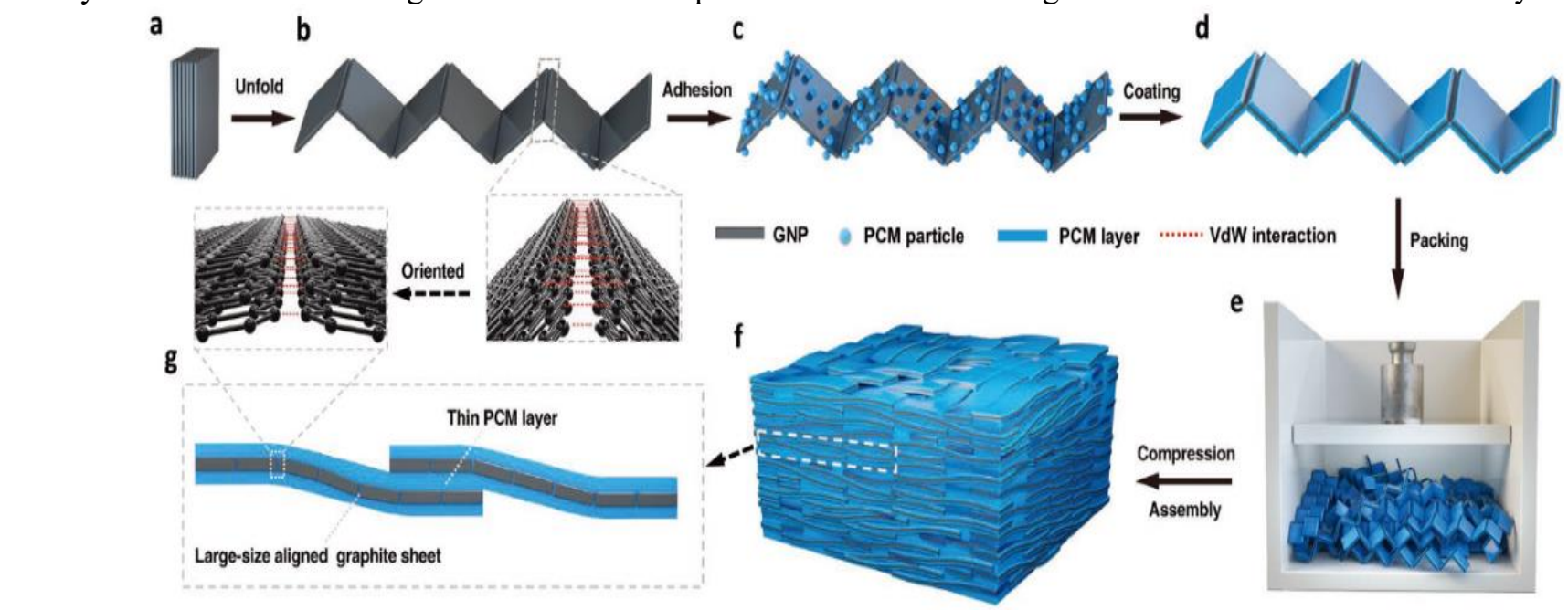

comprehensive properties of various materials including SSPCMs.

Realized by a facile organic solvent-free sacrificial template method, a flexible CNT hierarchical framework was constructed. ${ }^{[61]}$ The CNT framework showing interconnected pores further served as a supporting skeleton to absorb PEG. Exhibiting much practical value, the novelly developed CNT framework has a large capacity for fine particulate matter. With the support of CNT, the CNT/PEG SSPCM acquired excellent shape stability and reusability. In addition, the SSPCM was applied to regulate the temperature in thermotherapy which was kept at the plateau of $43.5^{\circ} \mathrm{C}$ for more than 30 minutes, achieving a remarkable thermotherapy effect.

Despite the advantages of CNTs, CNTs are an inherently inert material and easy to agglomerate and entangle due to the size and high aspect ratio, ${ }^{[62]}$ thereby, direct impregnation of PCMs into CNTs hardly made an ideal different to the good dispersion and following thermal conductivity enhancement, ${ }^{[63,64]}$ proper distribution or arrangement needs to be guaranteed. Plenty of new methods were developed to enhance SSPCM with CNTs and had made some progress.

To improve the thermal conductivity of SSPCM, Li et al. ${ }^{[65]}$ grafted the CNTs with an alcohol mixture (octanol, tetradecyl alcohol, and stearyl alcohol), the grafted CNTs acted to be supporting materials to impregnate the paraffin. Supported by the grafted treatment, the CNTs were revealed to have reduced length and better dispersion with fewer agglomerations which led to a reinforced thermal conductivity. Via a green DielsAlder reaction, single/multi-wall CNTs were functionalized by hexadecyl acrylate (HDA) to make HDA-g-SWCNT and HDA-g-MWCNT SSPCMs. ${ }^{[66]}$ The manufacturing process avoids the shortcomings of HDA including leakage during work, low thermal conductivity, and electrical isolation. In detail, the thermal conductivity shows $339 \%$ improvements and the electrical conductivity reaches $718 \mathrm{~S} / \mathrm{m}$ Moreover, the light-to-thermal performance of the SSPCMs was excellent with a max light-to-thermal conversion efficiency of $79.1 \%$.

Fig. 6 Schematic diagram to construct large-size oriented graphite and develop SSPCM. (Reproduced with permission from [60], Copyright 2021 Wiley) 

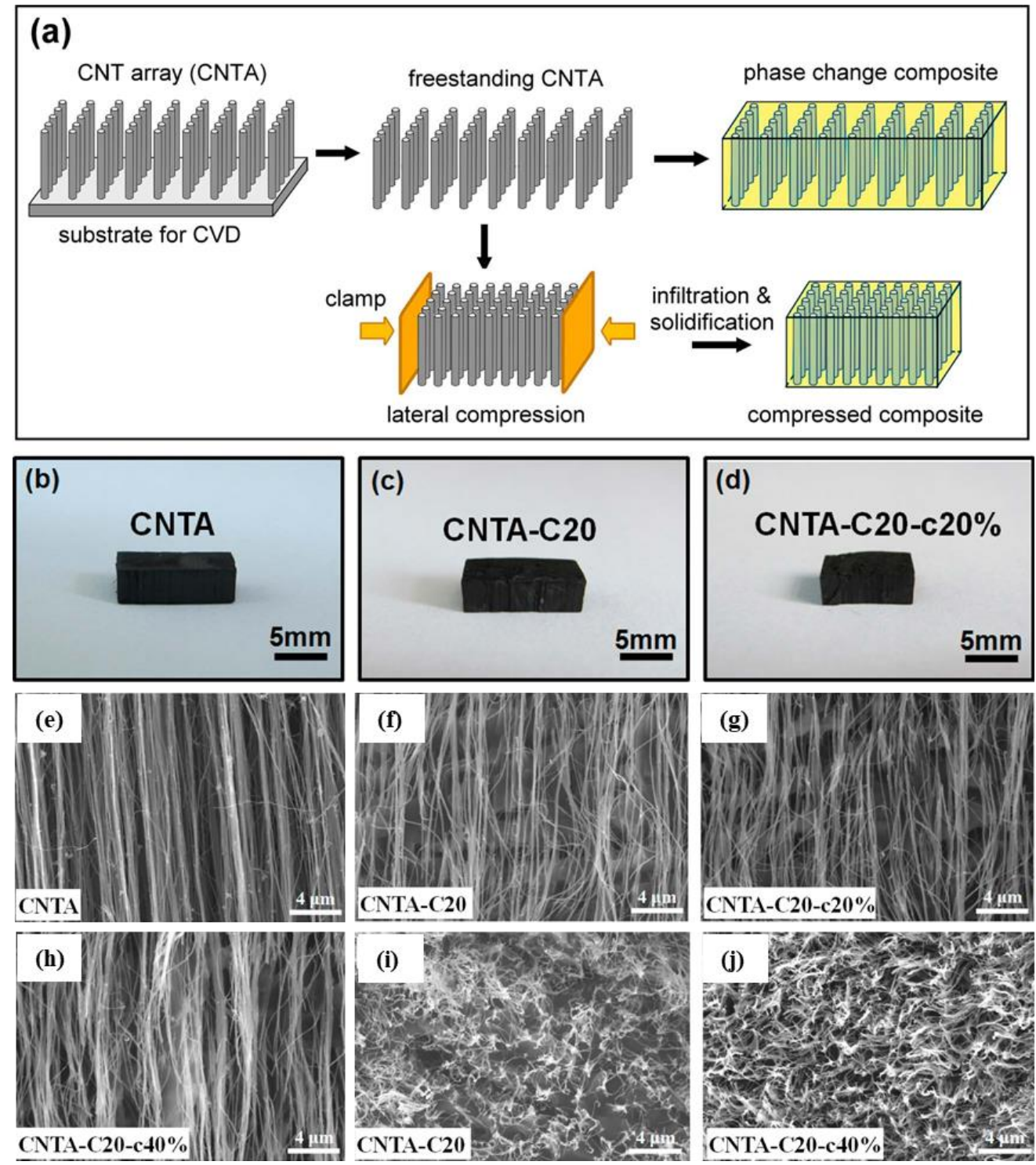

Fig. 7 (a) Fabrication scheme of CNTA-based SSPCM (b-d) digital pictures of CNTA, CNTA-C20, and CNTA-C20-c20\% (e-j) microstructures of CNTA, CNTA-C20, and CNTA-C20-c20\% and CNTA-C20-c40\%. (Reproduced with permission from [67], Copyright 2021 ACS)

By a chemical vapor deposition technique, a porous oriented CNTs array (CNTA) with an ordered anisotropic structure was designed to be a matrix to develop CNTA/C20 $\operatorname{SSPCM}^{[67]}$ (Fig. 7a). The structure exhibited a porous network in parallel and interval which provides enough space for $\mathrm{C} 20$ to fill in and achieved about $90 \mathrm{wt} . \% \mathrm{C} 20$ loadings in original and compressed CNTA-C20 composites. For both before and after compression, the CNTA-C20 SSPCM could keep the shape steady (Figs. 7b-d). After experiencing lateral compression at strains of $20 \%$ and $40 \%$, the density of CNTs became dense (Figs. 7g-j). Meanwhile, the CNTA-C20 SSPCM gets a thermal conductivity of $1.89 \mathrm{~S} / \mathrm{m}$ and it can harvest electricity at voltages as low as $1 \mathrm{~V}$ with efficiencies up to $74.7 \%$.

Qian et al. ${ }^{[68]}$ investigated the different effects of singlewalled CNTs and graphene nanoplatelets (GNPs) on the PEGbased SSPCM, respectively. Interestingly, the SSPCM with 8 wt.\% single-walled CNTs displayed comparable performance compared with SSPCM with 4 wt.\% GNPs. The similar performances for CNTs and GNPs include: (a) latent heat value $(92 \%$ and $96 \%$ of pure PEG), (b) thermal enhancement (950\% and $1096 \%$ of pure PEG), and (c) solar-to-light conversion efficiency $(78 \%$ and $86 \%)$. On the research condition, the GNPs were announced to be more efficient to enhance the SSPCMs, especially on the above parameters. The author attributed the differences to the filler dimension difference, providing some new insight into the development of SSPCM with better performance.

\section{Graphene}

Graphene as well has a trend to agglomerate similar to CNTs. Thereby compared with modification and blend methods, the ideal pattern of a graphene skeleton is to construct a highly thermally conductive 3D structure. ${ }^{[69,70]}$ However, too much loading of graphene would lead to agglomeration while low loading results in imperfect $3 \mathrm{D}$ interconnected structures. To 


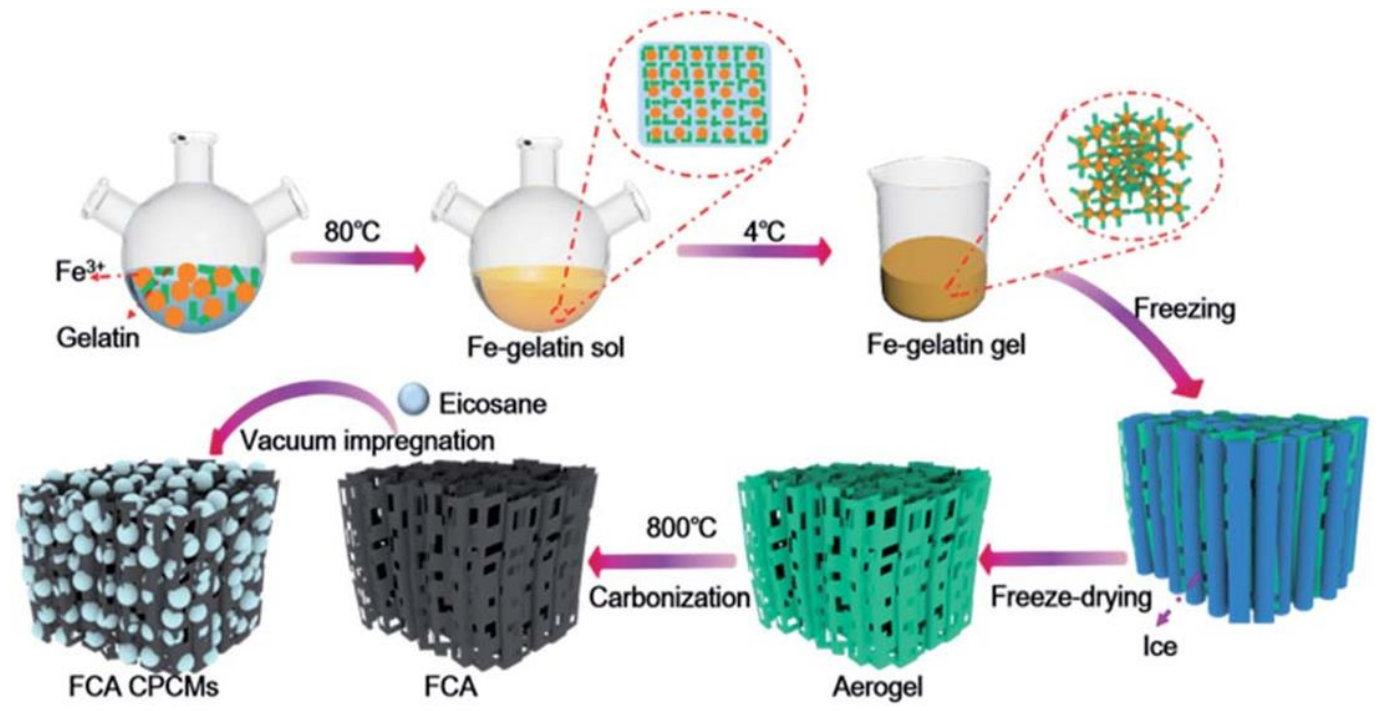

Fig. 8 Scheme of SSPCMs fabrication based on Fe-doped carbon aerogel. (Reproduced with permission from [71], Copyright 2021 RSC)

disperse graphene evenly and build a continuous conduction pathway, graphene aerogels (GAs), foams, sponges, and graphene derivatives are introduced into SSPCMs. ${ }^{[72-74]}$

Sun et al..$^{[71]}$ designed a Fe-doped carbon aerogel (FCA) as supporting materials to fabricate FCA/PW SSPCM whose PW weight absorption was as high as $85.80 \%$ and latent heat reached $212 \mathrm{~J} / \mathrm{g}$ (Fig. 8). Apart from leakage-proof property, the SSPCM hardly lost any weight after 1000 cycles, replying the significant reusability. In addition, with benefits to the continuously conductive pathway and Fe element, the SSPCM exhibited a strong response to the solar, electric, and magnetic energy in which the electron-to-thermal conversion efficiency was calculated to be up to $94.83 \%$, revealing its great efficiency to convert electricity into thermal energy. The multi-responsive SSPCM has a board application in the energy storage field.

Wei et al. ${ }^{[75]}$ fabricated a well-defined 3D GA with the assistance of lignin which could stabilize the shape of the GA. The lignin-modified GA was used to absorb PEG with a remarkably high weight fraction $(99.0 \%)$ which is higher than that of previous GA-based SSPCMs. Meanwhile, the SSPCMs not only acquired reinforced light absorption from NIR to UV light but also exhibited high latent heat efficiency (96.71\%) and relative latent heat efficiency $(98.41 \%)$, both of the aforementioned factors could contribute to the good solar-tothermal conversion.

Liao et al. ${ }^{[76]}$ prepared a light-weight GA which was cocarbonized with MF. The GA/MF composites served as supporting materials to impregnate PEG. Attributing to the interconnect structure of $\mathrm{MF}$, the resulting $\mathrm{GA} / \mathrm{MF} / \mathrm{PEG}$ SSPCM obtained an enhanced thermal conductivity (1.32 W/m K) compared with GA/PEG SSPCM $(0.79 \mathrm{~W} / \mathrm{m} \mathrm{K})$. Moreover, the GA/MF/PEG SSPCM acquired excellent shape stability and the GA/MF/PEG SSPCM could stabilize the shape at $100{ }^{\circ} \mathrm{C}$ while the GA/PEG entirely deformed. The combination of MF and GA broadened the application of
SSPCM.

In Chen's work, ${ }^{[35]}$ graphene sponge was adopted to absorb two kinds of fatty amine to fabricate SSPCMs, resulting from the super low density of graphene sponge, the SSPCM achieved a loading rate as high as 7063-10660 wt.\% compared to a fatty amine. Additionally, both of the SSPCMs show high energy storage and low supercooling which ranges from 7$9{ }^{\circ} \mathrm{C}$, the materials could be a good candidate for energy storage.

Tian and coworkers ${ }^{[7]}$ employed the GA to absorb octadecanoic acid (OA) with a weight fraction of $85 \%$ to construct SSPCMs. Interestingly, the SSPCM has a thermal conductivity $(2.635 \mathrm{~W} / \mathrm{m} \mathrm{K})$ with 20 vol.\% GA, about 14 times that of the OA. The latent heat of the material reaches $181.8 \mathrm{~J} / \mathrm{g}$, almost equal to the value of the pristine OA (186.1 $\mathrm{J} / \mathrm{g}$ ), showing great crystalline OA. The phenomenon that the loading of GA hardly affects the phase change entropy of SSPCMs is different from other works.

Using a similar method, Wang and coworkers ${ }^{[78]}$ found that beyond a $0.5 \mathrm{wt} . \%$ threshold, GAs could possess a cellular architecture with a high degree of alignment. The GA skeleton endows the SSPCMs with ameliorated mechanical properties and fracture toughness. Besides, the SSPCM shows a remarkable electrical conductivity $\left(2 \times 10^{-3} \mathrm{~S} / \mathrm{cm}\right)$ with only 0.25 wt. \% graphene, significantly higher than those of the composites produced by direct dispersion of GNPs or rGO into the matrix.

\subsubsection{Biomass}

There are lots of works that received inspiration from nature. Biomass, a natural production, could also be used as supporting material. The biomass always consists of special structures like pores, conduits, and cavities which could provide not only space to absorb PCM but also sites for modification. ${ }^{[79]}$ In addition, biomass is an eco-friendly material that is underutilized and produces vast pollution 


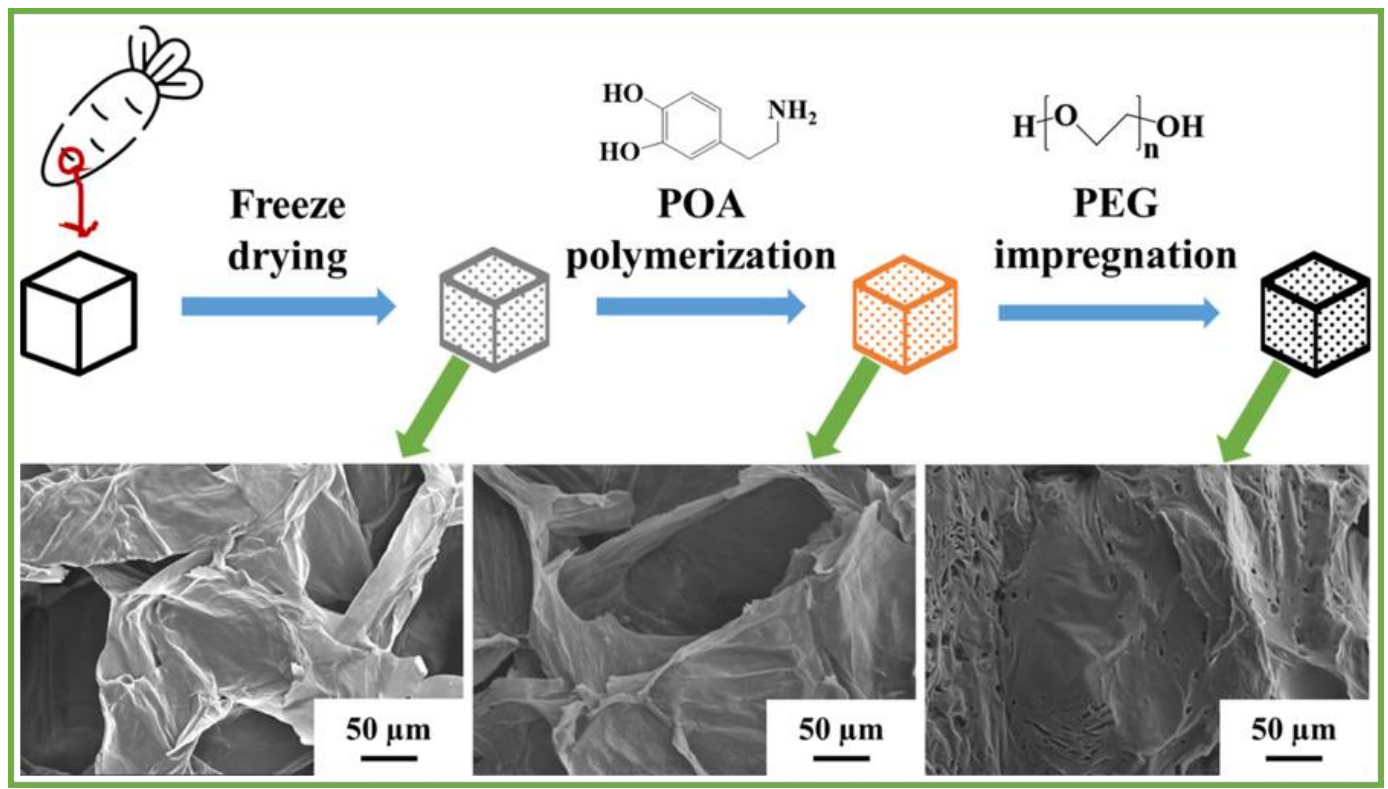

Fig. 9 Fabrication illustration and SEM images of radish-based SSPCMs. (Reproduced with permission from [80], Copyright 2021 ACS)

without proper treatment. Various biomass was used to fabricate SSPCMs and shows excellent properties.

Atinafu et al..$^{[81]}$ developed a multiwalled carbon nanotube/n-dodecane SSPCM with a one-step hydrothermal method, the SSPCM achieved an 83.2\% PCM loading and latent heat $152.3 \mathrm{~J} / \mathrm{g}$. The SSPCM simultaneously could hold the PCM and stabilize the shape steadily.

Xie et al. ${ }^{[80]}$ developed a PDA-modified freeze-dried radish, the radish matrix exhibited a well-defined porous structure which was used as supporting material to absorb PEG and the weight content of PEG reached $76.45 \%$ (Fig. 9). The radish/PDA/PEG SSPCM obtained a sandwich structure which could prove the strength of the SSPCM and avoid the PEG leakage during energy storage and release process. Besides, with the introduction of PDA, the SSPCM achieved a strong absorption in a wide light wavelength, showing great potential in thermal energy storage.

$\mathrm{Hu}$ et al. ${ }^{[82]}$ reutilized the reduced graphene oxide (rGO)modified spent coffee ground as a matrix to impregnate PEG, the SSPCM shows excellent shape stability and ignorable leakage during phase change. In addition, with the rGO modification, the SSPCM shows enhanced thermal conductivity and solar energy harvest ability. The work inspires the reutilization of biomass waste.

Wood is another matrix exploited in SSPCM, Qiu et al. ${ }^{[83]}$ produced a transparent wood (TW) with the assistance of a styrene/butyl acrylate network to stabilize the 1-octadecene PCM via copolymerization. The TW material was revised from opaque to transparent with the phase change process and the haze could be switched. Coupled with excellent flexibility attributed to the introduction of soft crosslinking networks which could, the material promises possible optical implement.

Wen et al. ${ }^{[84]}$ used diatomite to absorb CA-LA and added EG was added to enhance thermal conductivity. The thermal conductivity of CA-LA/diatomite contained $10 \mathrm{wt} . \%$ EG was successfully increased by $113.2 \%$ compared with CALA/diatomite. However, the thermal enthalpy decreased due to the less impregnation ratio of PCMs in the composites. To simultaneously prove thermal conductivity and impregnation ratio, ${ }^{[35]}$ EG was introduced as a support matrix together with diatomite at a weight ratio of 1:10 (EG to diatomite), devised LA-SA/ diatomite /EG SSPCM with 72.2\% loading rate of LA-SA acquired a phase change temperature of $31.17^{\circ} \mathrm{C}$, the material also showed latent heat value of $117.30 \mathrm{~J} \mathrm{~g}^{-1}$ for melting and $114.50 \mathrm{~J} \mathrm{~g}^{-1}$ for freezing. The thermal conductivity of LA-SA/ diatomite /EG was up to 3.2 times that of LA-SA/ diatomite.

Other biomass like pepper, ${ }^{[85]}$ diatom, ${ }^{[86]}$ eggplant $^{[87]}$ even cotton is introduced into the SSPCM and were reported to have good shape stability. The biomass and its derivates still have sufficient value to be researched.

\subsubsection{Others \\ Boron nitride (BN)}

$\mathrm{BN}$ possesses a similar crystal structure to graphene showing high thermal conductivity, ${ }^{[88]}$ it was adopted into the SSPCM fabrication as well.

Qian et al. ${ }^{[89]}$ impregnated the h-BN porous skeleton with 72 wt.\% PW to manufacture SSPCMs. Relying on the continuous thermal conductive paths of h-BN scaffolds, the thermal conductivity increased by six folds $(0.85 \mathrm{~W} / \mathrm{m} \mathrm{K})$. In addition, the resulting SSPCM could stabilize the shape after melting with the support of the h-BN skeleton.

Yang and coworkers ${ }^{[90]}$ employed PDA-modified BN as supporting materials to obtain SSPCM. With the modification of PDA, the BN was better dispersed into the SSPCM which resulted in a thermal enhancement. Besides, the SSPCM exhibited excellent shape stability, light harvest, and electrical 


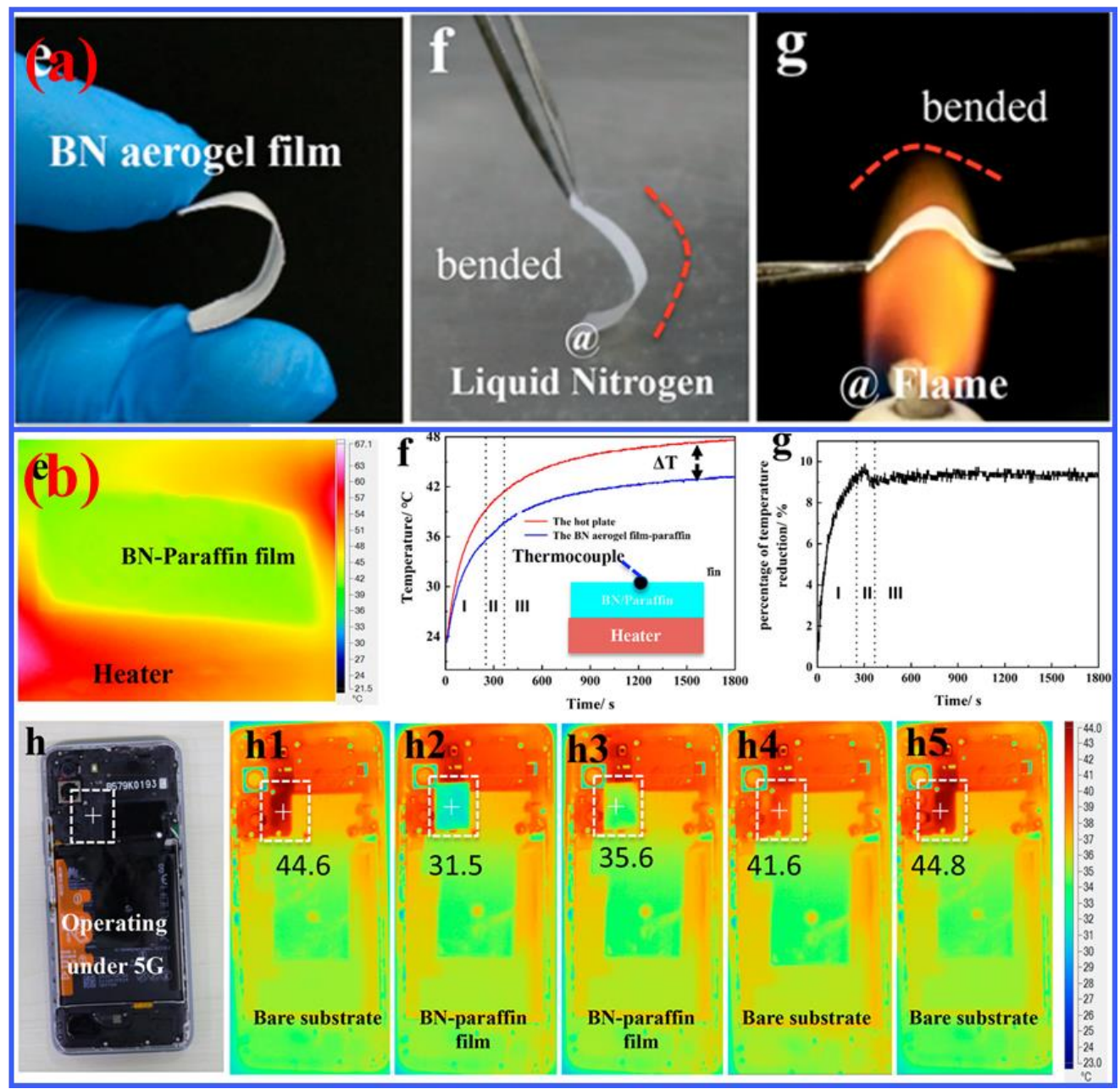

Fig. 10 Flame-retardant of BN aerogel and thermal management properties of BN-paraffin SSPCMs. (Reproduced with permission from [91], Copyright 2021 ACS)

insulation, endowing the SSPCM with better energy conversion and storage ability.

To increase the interfacial adhesion, Wie et al. ${ }^{[92]}$ exploited the PVA to load on the surface of BN, then the BN/PVA composite was driven to absorb PEG which would react with PVA to assist heat conduction. As a result, the mobility of PEG chains was limited leading to a reduction of latent heat. However, the thermal conductivity of BN/PVA/PEG SSPCM increased by $286 \%(0.89 \mathrm{~W} / \mathrm{m} \mathrm{K})$ compared to pure PEG, and the crosslinking method was believed to be an efficient way to improve interfacial adhesion.

Via the ice-templated self-assembly strategy, BN@chitosan scaffolds were obtained to encapsulate PEG, ${ }^{, 93}$ apart from high phase change enthalpy and outstanding thermal repeatability, the SSPCM acquired a thermal conductivity of $2.78 \mathrm{~W} \mathrm{~m}^{-1} \mathrm{~K}^{-1}$ which is $804 \%$ higher than that of pure PEG. It was assumed to be caused by effective thermal conductive pathways in the resultant scaffolds. The work revealed a novel method to construct 3D continuous skeletons.

Wang et al. ${ }^{[91]}$ firstly developed a flexible $\mathrm{BN}$ aerogel with $96 \%$ porosity and a large specific surface area (Fig. 10). Serving as a thermal insulation, the BN aerogel could well resist fire (Fig. 10a). In addition, the porous structure endows the aerogel with low thermal conductivity which diffused heat slowly in electronics. Then, the $\mathrm{BN}$ aerogel was employed to absorb paraffin with a high content (79.3 wt.\%) to manufacture SSPCM. The SSPCM shows obvious thermal management properties on a smart $5 \mathrm{G}$ phone whose temperature was always below the control sample and the max temperature gap was only $6{ }^{\circ} \mathrm{C}$ (Fig. 10b).

Usman and Ahmed have reviewed the fabrication and properties of SSPCMs based on BN and carbon derivates such as graphene, expanded graphite, and carbon nanotubes ${ }^{[21]}$. As summarized, the BN-based SSPCMs always have a lower thermal conductivity compared with carbon-based SSPCMs. The BN was reported to enhance the thermal conductivity with less efficiency although other performances are comparable. However, the boron nitride still serves as a promising filler attributed to its excellent thermal properties.

\section{MXene}

MXene, a kind of 2D transition metal carbides/nitrides material with a thickness of a few atomic layers, is newly used in the development of SSPCMs for its high specific surface area, large layer spacing, rich hydrophilic groups, and 


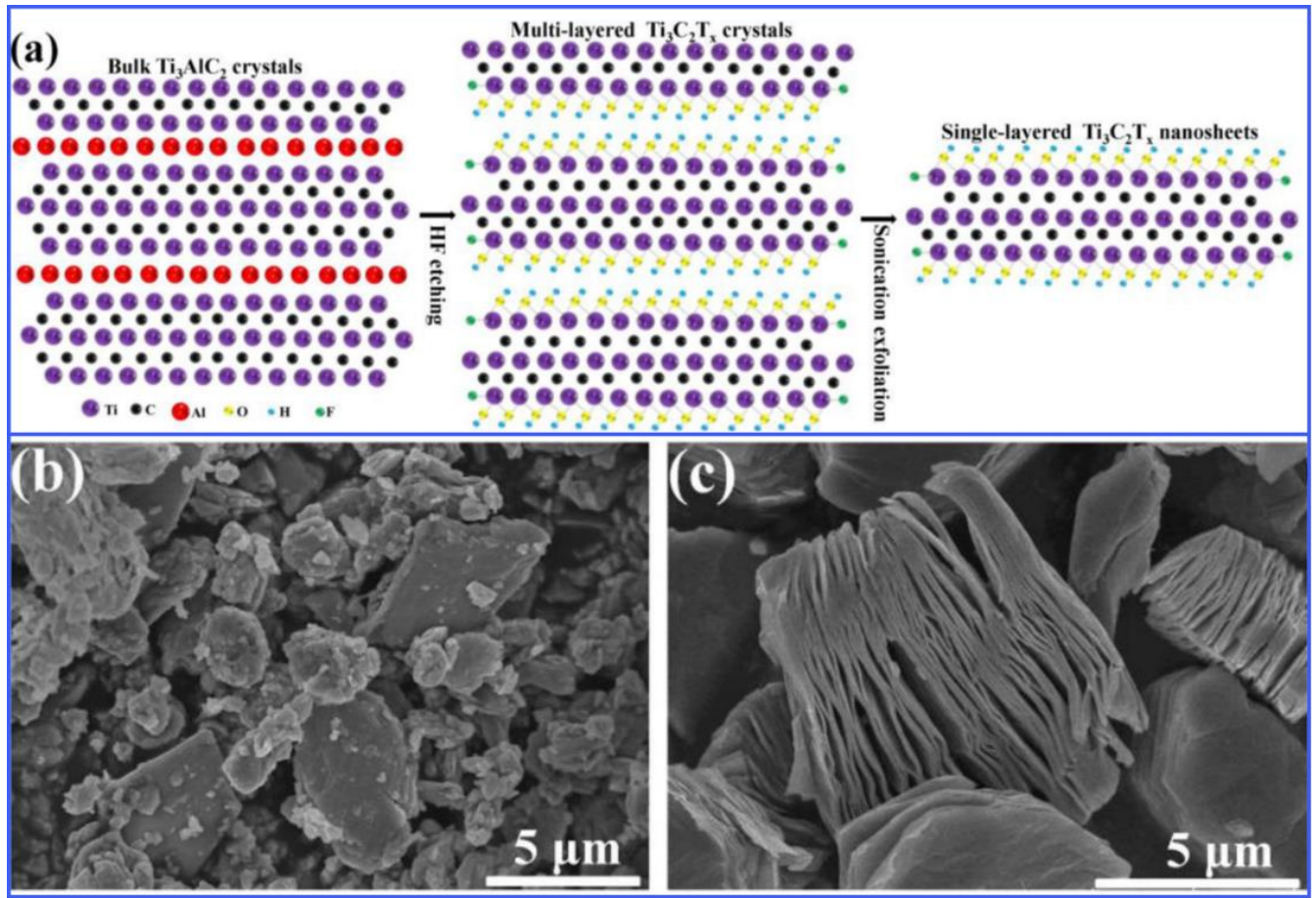

Fig. 11 (a) Structural illustration of the fabrication of MXene and (b) SEM pictures of $\mathrm{Ti}_{3} \mathrm{AlC}_{2}$ crystals and layered structure of MXene.

excellent electrical and thermally conductive properties. ${ }^{[94]}$ Multilayer $\mathrm{Ti}_{3} \mathrm{C}_{2} \mathrm{~T}_{\mathrm{x}}$ MXene is mainly developed by $\mathrm{HF}$ etching, ${ }^{[95]}$ the illustration and SEM morphology is shown in Fig. 11.

There are plenty of works concerning MXene in the literature about SSPCM development. MXene was first used as the supporting skeleton as well as thermally and electrically conductive filler to encapsulate PEG by $\mathrm{Lu}$ and coauthors. ${ }^{[96]}$ Apart from an $80.3 \%$ enthalpy efficiency, the resulting SSPCM shows great thermal and electrical conductivity enhancement, showing high light harvest ability. In other work, light-weight MXene aerogel was employed to absorb PEG, the MXene/PEG SSPCM reaches a relatively high photothermal conversion whose value is $92.5 \% .^{[95]}$ The above works demonstrate MXene is a good matrix for SSPCM.

Apart from receiving a light-weight MXene@PEG whose density is about $30 \mathrm{mg} / \mathrm{cm}^{3}$, the MXene nanosheets improve the thermal stability of PEG at the same time, the thermal decomposition temperatures can be increased by $40{ }^{\circ} \mathrm{C}$. ${ }^{\text {95] }}$ Besides, the actual fusion and solidification enthalpies of MXene@PEG aerogels reach 167.72 and $141.51 \mathrm{~J} / \mathrm{g}$, respectively. The photothermal storage efficiency of MXene@PEG aerogels reaches a relatively high value of $92.5 \%$.

Only a dope of 0.3 wt.\% MXene to PW was revealed to enhance specific heat capacity with a value of $43 \%$ and thermal conductivity of $16 \%$ compared to the pure PW70. ${ }^{[97]}$ In a 3D porous skeleton system, MXene and bacterial cellulose (BC) were combined as supporting material to encapsulate PEG, the BC-MXene/PEG SSPCM exhibited efficient photothermal conversion ability and extremely high energy storage capacity, which sheds substantial light on the efficient utilization of solar energy. ${ }^{[98]}$ As a popular 2D material, the MXene still leaves huge space to explore.

\section{Hybrid system}

The single component of carbon materials was difficult to achieve a continuous conductive pathway. Thus, the hybrid system of carbon materials was adopted to solve the problem with a synergetic effect. ${ }^{[99]}$

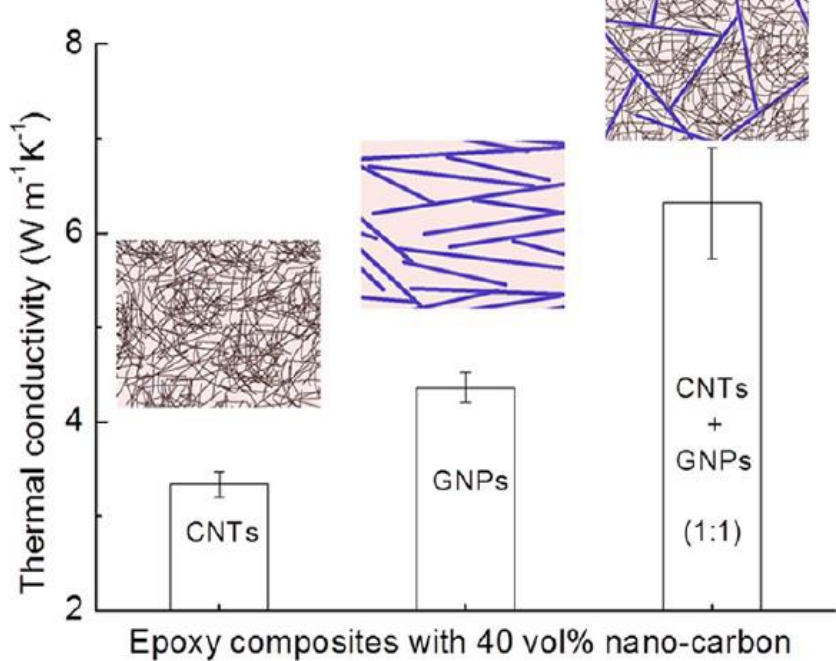

Fig. 12 Thermal conductivity of SSPCMs with 50 vol.\% CNTs, 50 vol. $\%$ GNPs, and 20 vol. $\%$ CNTs $/ 20$ \& vol. $\%$ GNPs. (Reproduced with permission from [100], Copyright 2021 ACS).

The graphene and CNTs hybrid systems have attracted extensive attention since their first publication. ${ }^{[101]}$ In an epoxy 
composite, the composite with 20 vol.\% CNTs and 20 vol.\% GNPs possess a thermal conductivity of up to $6.31 \mathrm{~W} / \mathrm{m} \mathrm{K}$ which is much higher than that of the composites with individual 50 vol. $\%$ CNTs or 50 vol.\% GNPs $^{[100]}$ (Fig. 12). The authors attributed the unusual thermal conductivity enhancements to the high quality of the composite samples in which the effective bridging between GNPs with CNTs and the nonoriented dispersion of GNPs induced by CNTs were achieved. The bridging and better dispersion drove the continuous conductive pathway constructed successfully.

In a copper foam/PW hybrid system, ${ }^{[47]}$ the CNT was coupled with EG. Through growing long CNT networks directly from the graphite struts of ultrathin graphite foams (UCFs) into the pore space, UGF@CNT matrix achieved extraordinarily high absorption of erythritol which reaches 98.2 wt.\%, the UGF-CNT/erythritol SSPCM got a significant thermal conductivity enhancement. With the dope of $0.68 \mathrm{wt} . \%$ $\mathrm{CNT}$, the thermal conductivity was promoted to $3.49 \mathrm{~W} / \mathrm{m} \mathrm{K}$ from $0.105 \mathrm{~W} / \mathrm{m} \mathrm{K}$ of PW. From $2.26 \pm 0.1 \mathrm{~W} / \mathrm{m} \mathrm{K}$ to $4.09 \pm$ $0.3 \mathrm{~W} / \mathrm{m} \mathrm{K}$, increasing by as much as a factor of 1.8 compared to that of a UGF/erythritol composite.

Huang et al. ${ }^{[102]}$ produced $\mathrm{rGO} / \mathrm{BN}$ anisotropic aerogels to impregnate $\mathrm{PW}$, the obtained SSPCM acquired a thermal conductivity of $1.68 \mathrm{~W} / \mathrm{m} \mathrm{K}$ which was as higher as $504 \%$ than $\mathrm{PW}$. In addition, the $\mathrm{rGO} / \mathrm{BN} / \mathrm{PW}$ SSPCM experienced phase change without any leakage, and the $\mathrm{rGO} / \mathrm{BN}$ matrix was revealed to improve the energy storage efficiency of SSPCM. The hybrid system proved to be more efficient than single components.

\subsection{Encapsulation}

Another effective fabrication method to avoid PCMs from leakage and keep it from the atmosphere is the encapsulation method in which envelopes liquid droplets or fine solid particles to form microscopic capsules $1 \mathrm{~nm}$ to $1000 \mathrm{~nm}$ (nanocapsule) and $1 \mu \mathrm{m}$ to $1000 \mu \mathrm{m}$ (microcapsule) in diameter. As depicted in Fig. 13 the capsules compose of twopart in which the core locates in the center and the shell is on the outside.

The origin of the method could date back to the 1950s by Barret. ${ }^{[103,104]}$ Now it is even used in perovskite to fabricate solar cells out from ambient air and humidity. ${ }^{[105,106]}$ In the fabrication of SSPCMs, the method is employed to coat PCM in a shell, which further evades the causticity and phase separation of PCMs. Three major categories of the method are denoted as physical, chemical, and physicochemical methods.

\subsubsection{Physical method}

Physical microencapsulation is not associated with chemical reactions. The method consists of sprays drying and fluidized bed.

Spray drying is a continuous and scalable drying process to encapsulate materials, the process can generate nano to micron-size particles that have a narrow distribution in a very short time. ${ }^{[107]}$ It has been used in pharmaceutical processing ${ }^{[108-110]}$ and the food industry ${ }^{[111]}$ for a long time. The main advantage of spray drying is the waste reduction and the high efficiency of raw materials. Besides, the size distribution of resulting products could be controlled ${ }^{[112,113]}$ as well as the scale of manufacture can be designed is of great benefit to industrial production. ${ }^{[14]}$ Borreguero $^{[115,116]}$ did some work using spray drying to encapsulate PW, the method was confirmed to be able to encapsulate PW into carbon nanofibers shell, the nanofiber/PW SSPCMs have excellent cycling performance which could melt and solidify reversibly during 3000 cycles. Nizori et al. ${ }^{[117]}$ produced ascorbic acid (AA) microcapsules through spray drying, the obtained microcapsules exhibit a well-defined sphere shape, in addition, the microcapsule SSPCMs exhibited a loading content of AA as high as $54 \%$.

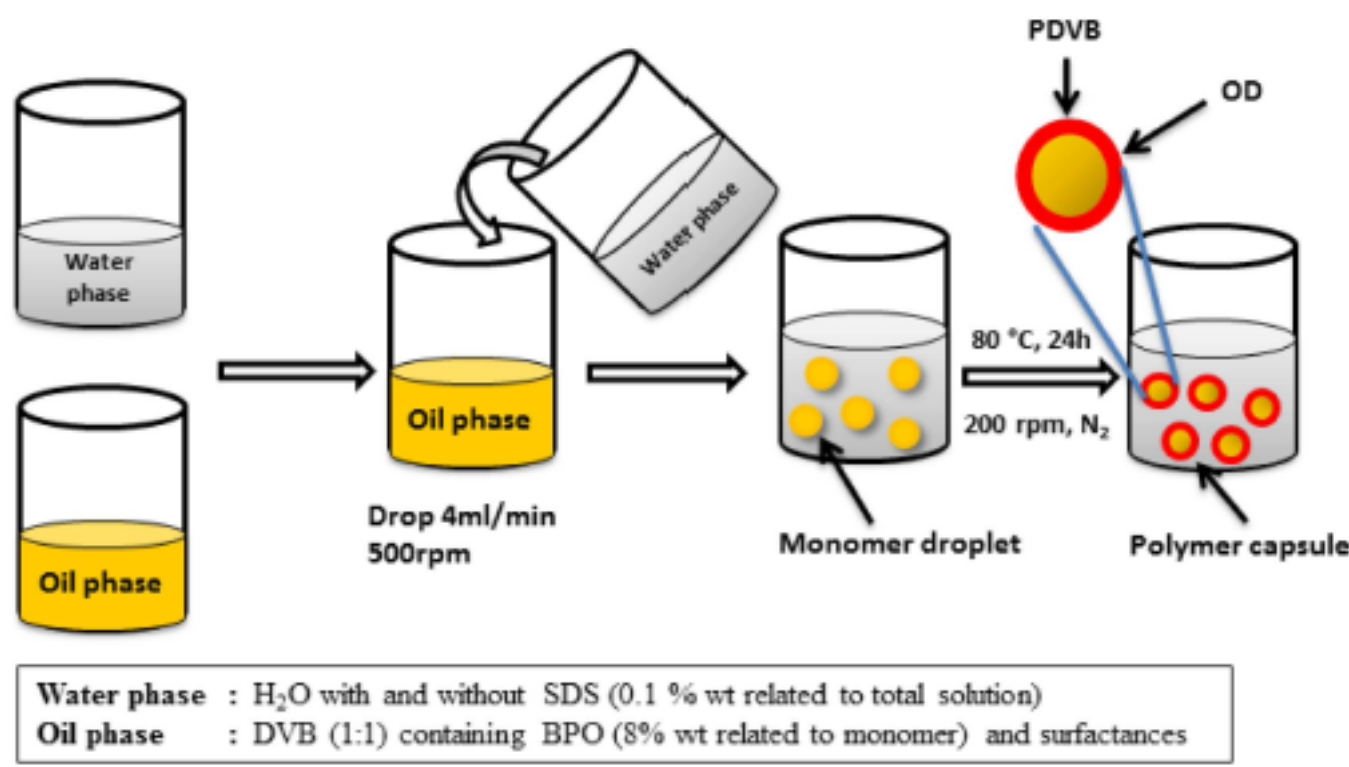

Fig. 13 Encapsulation using micro-suspension polymerization. (Reproduced with permission from [118], Copyright 2021 RSC) 
A typical spray-drying system consists of various components, and the choices of components and operating parameters have a crucial influence on the process output. In addition, the process requires professional equipment which makes the procedure kind of complex and extra effort is needed to learn about the mechanical, thus applications of spray drying in manufacturing SSPCMs are not widespread.

The fluidized bed method has been used in food ${ }^{[119]}$, agriculture ${ }^{[120],}$ and corrosion protection before. ${ }^{[121]}$ However, only several essays about SSPCMs manufacture are

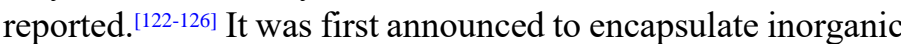
PCMs in 1998. ${ }^{[127,128]}$ Then the method was employed to encapsulate organic PCM Paulo ${ }^{[129]}$ and proved to be a wellestablished protocol to coat carnauba wax, the resulting composites with proper encapsulation material could maintain initial shapes beyond $100{ }^{\circ} \mathrm{C}$. However, the final properties of SSPCMs are associated with the good operation of fluidized beds, while the equipment is of a big scale. ${ }^{[130]}$ Thereby, the method does not widespread to use in encapsulating PCMs.

\subsubsection{Chemical method}

In contrast to the complicated setup of the physical method, chemical methods gain much attention attributing to simple processes and convenient setup in the laboratory. The chemical microencapsulation takes place during in-site polymerization ${ }^{[131,132]}$, which involves emulsion, ${ }^{[133]}$ interfacial, and suspension polymerization. In addition, the chemical method enables the shell to cover the core more evenly. Both process and ratio of shell to the core are much easier to control.

Emulsion polymerization is the most widely used encapsulation method. Typically, Zhang et al..$^{[134]}$ used a PEO-PPO-PEO triblock copolymer reacting with acrylate via emulsion polymerization to encapsulate PW-based SSPCM. The SSPCM exhibits latent capacity as high as $220 \mathrm{~J} / \mathrm{g}$ and excellent reusability as well as energy storage. Kurniawan et $a l . .^{[135]}$ successfully produced SSPCM nanocapsules with ureaformaldehyde shells and PEG cores through emulsion polymerization. The SSPCM could be applied to fabrics and keep the temperature steady to maintain comfort. By using emulsion polymerization and modified phosphorus-based flame retardant DEAMP as the crosslinking agent, novel octadecane/PMMA SSPCMs were successfully fabricated. ${ }^{[136]}$ The SSPCMs possessed high encapsulation efficiencies for $\mathrm{n}$ octadecane in the range of $86.5 \%$ to $94.0 \%$. The addition of DEAMP was proved to significantly suppress the heat as well as smoke releases and meantime showed great potential in thermal energy storage.

Using suspension polymerization, ${ }^{[137]} \mathrm{PMMA} / \mathrm{n}$-dodecanol shell/core microencapsulated SSPCM was developed in which the effects of different emulsifiers and crosslinking agents were also investigated. The average SSPCM particle size is $14.18 \mu \mathrm{m}$. Additionally, the SSPCM achieved a high encapsulation yield and excellent shape stability.

Zhao et al. ${ }^{[138]}$ prepared a novel polystyrene-shelled SSPCM with two kinds of paraffin via soap-free emulsion polymerization. The SSPCM obtained two phase change temperature ranges and encapsulation reached $91.28 \%$ in which the average diameter of capsules was $136 \mathrm{~nm}$. Using the building comfort, the SSPCM could suffice the indoor temperature adjustment in both winter and summer.

Through interfacial polymerization ${ }^{[139]}$, a novel polyurethane (PU) microencapsulated methyl laurate SSPCM was obtained with an encapsulation efficiency as high as $75.18 \%$. The SSPCM exhibits excellent thermal reliability and storage stability, moreover, the work comprehensively explored offers inspiration for the development of SSPCM with interfacial polymerization.

Zhu et al.$^{[140]}$ firstly manufactured a PW core stabilized by regenerated nanochitin (RCH), the core subsequently interfacial polymerized with isocyanate to fabricate SSPCMs whose encapsulation efficiency and latent heat reached as high as $91.3 \%$ and $230 \mathrm{~J} / \mathrm{g}$, respectively. The average diameter and shell thickness could be tuned by changing the isocyanate and $\mathrm{RCH}$ concentrations. Besides, the SSPCM showed excellent thermal management on the processor of mobile phones.

\subsubsection{Physico-chemical method}

The other technique to encapsulate PCMs is a sol-gel method in which a polydensation reaction is launched firstly to form a homogenous solution and then the solution turns to gelation. Chen et al. ${ }^{[141]}$ used the sol-gel method to encapsulate stearic acid with $\mathrm{a} \mathrm{SiO}_{2}$ shell, the resulting composites encapsulate $90.3 \%$ of stearic acid which is a significantly high absorption rate. At the same time, the $\mathrm{SiO}_{2}$ shell improves the thermal stability of composites and restrains the flammability of stearic acid.

In a $\mathrm{TiO}_{2} / \mathrm{C} 20$ system, ${ }^{[142]}$ via a nonaqueous oil-in-water $(\mathrm{O} / \mathrm{W})$ emulsion templating method, SSPCM with $\mathrm{C} 20$ core surrounded by $\mathrm{TiO}_{2}$ shell was fabricated in the sol-gel process. In the case, the formed SSPCM not only has a perfectcoreshell structure but also achieves the crystalline $\mathrm{TiO}_{2}$ shell with photocatalytic effectiveness.

In a natural rubber system, ${ }^{[143]}$ a novel thermoregulated natural rubber was prepared by blending the water suspension of the encapsulated C20/ethyl cellulose/methyl cellulose (C20/EC/MC) microparticles with natural latex (Fig. 14). The obtained PCM/rubber composite exhibits remarkable thermoregulation property which could keep over $30^{\circ} \mathrm{C}$ for more than 40 minutes which the control dropped to $29^{\circ} \mathrm{C}$ in 15 minutes for $46{ }^{\circ} \mathrm{C}$. In addition, at the same strain, the $\mathrm{PCM} /$ rubber composite could maintain a higher stress value, it also outweighs control rubber by $25 \%$ in breaking elongation.

The shell sometimes could endow the capsules with novel functions. In a $\mathrm{ZrO}_{2}$ system, the $\mathrm{C} 20$ was encapsulated into a $\mathrm{ZrO}_{2}$ shell by in-situ polycondensation. ${ }^{[26]}$ The $\mathrm{ZrO}_{2} / \mathrm{C} 20$ SSPCM could generate purple-colored and green-colored luminescence after being excited by UV radiation. Inorganic matrix still owns unique characteristics which in the future could be combined with SSPCM. Via an emulsion method 
starting with the $\mathrm{Te} / \mathrm{W}$-codoped $\mathrm{VO}_{2}$ microparticles, the $\mathrm{PW} @ \mathrm{VO}_{2}$ SSPCM for the first time was developed. ${ }^{[27]}$ The $\mathrm{SSPCM}$ shows suitable $\mathrm{Tc}=58.2^{\circ} \mathrm{C}$ and a decent fusion latent heat of $163 \mathrm{~J} / \mathrm{g}$. The doped $\mathrm{VO}_{2}$ matrix endows the SSPCM with high conductivity which reveals a new method and new matrix to fabricate SSPCM. The encapsulation method increases the diversity of SSPCMs with new functions.

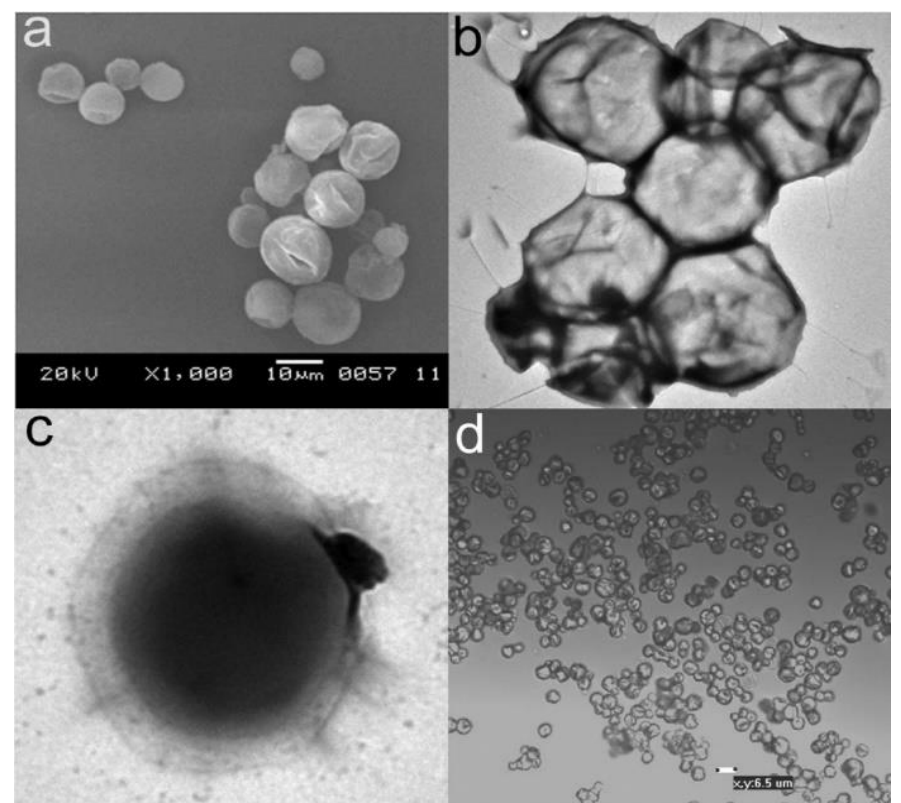

Fig. 14 Representative (a) SEM, (b, c) TEM, and (d) optical microscopic images of the $\mathrm{C} 20 / \mathrm{EC} / \mathrm{MC}$ particles prepared with a $9 \%(\mathrm{w} / \mathrm{w})$ polymer content. (Reproduced with permission from [143], Copyright 2021 ACS)

\subsection{Polymer shaping}

Polymers are widely used in daily life, the properties such as viscoelasticity are extraordinary and unique to an inorganic matrix which enables SSPCMs to resist ambient influence and even acquire distinctive new features. Plastics and rubber are two main categories of polymer, both of which could be employed as a matrix for SSPCMs, and the resulting SSPCMs exhibit various potentials.

Traditional plastic materials are promising materials to support PCMs. Both high- and low-density polyethylene are employed as a matrix to fabricate SSPCMs attributing to excellent mechanical properties and compatibility with organic PCMs.

$\mathrm{Mu}$ et $a l .^{[144]}$ investigated the impact of two PW with different phase change ranges on the SSPCMs. Interestingly, the PW with high melting temperature showed greater mechanical properties, irrespective of the mode of deformation, moduli, and stress after compositing with HDPE compared with the PW with low melting temperature. Besides, the fabrication process was launched on twin screw extrusion which achieved industrial production. Lv et al. ${ }^{[145]}$ developed a kind of low-density polyethylene (LDPE)/EG/PW SSPCM and combined it with low fins to develop a novel battery thermal management system. The SSPCM was endowed with better mechanical and leakage-proof properties by LDPE supporting material. Moreover, the combination of LDPE/EG/PW SSPCM with low fins accelerated the thermal energy diffusion and dissipation which enhanced the temperature regulation property of the entire module.

Polymethyl methacrylate (PMMA) is a light weight polymer with high mechanical strength which was also used in SSPCM fabrication. ${ }^{[146]} \mathrm{Chen}^{[34]}$ uses ${ }^{[D V B-} \mathrm{SO}_{3} \mathrm{H}$ and PDVB- $\mathrm{SO}_{3} \mathrm{Na}$ as supporting materials to encapsulate ODA, showing extraordinarily high phase change entropy which reaches $437 \mathrm{~J} / \mathrm{g}$ which has never been reported before in organic PCMs.

For renewable concerns, biodegradable polymer PLA has been applied to support sodium carboxymethyl cellulosebased lauric acid to develop SSPCMs, ${ }^{[147]}$ the phase change temperature of SSPCM is closed to human body temperature, with the biocompatibility of PLA, the combination could be promising in artificial skin to improve comfort.

Rubber, well known for its high elasticity, endows the SSPCM with excellent flexibility which could help SSPCM deform into multiple shapes to fit into various occasions. Up to now, there are few traditional rubbers involved in the SSPCMs, Minna, et al. ${ }^{[148]}$ used to employ natural rubber as a supporting material and PW as a working substance to develop SSPCM. Other SSPCM mainly concerns the ethylenepropylene-diene monomer (EPDM) and silicone rubber.

Based on PST, our group ${ }^{[149]}$ developed a series of flexible EPDM-based SSPCMs through melt-mixing in the preliminary work. Except for excellent leakage-proof properties and flexibility, the obtained SSPCMs acquired good shape recovery to recover initial shape upon thermal stimulus in which EPDM with lasting strong resilience was used as the "soft phase" and PW with phase change property as the "hard phase". The polymer could endow the SSPCMs with many novel features. Chen et al. ${ }^{[150]}$ mixed polyethylene and EPDM as a polymer matrix to prepare the $\mathrm{PW} / \mathrm{EG}$ composite by extrusion technology. The SSPCM exhibits a tensile strength of $8.1 \mathrm{MPa}$ and a bending strength of $14.7 \mathrm{MPa}$ which is much higher than that of other SSPCMs.

Silicone rubber is a novel kind of rubber whose backbone is made of silicon and oxygen atoms, the rubber was always introduced into SSPCM fabrication. To absorb more PCMs, silicone rubber was combined with $\mathrm{SiO}_{2},{ }^{[151]}$ the silicone rubber and the $\mathrm{SiO}_{2}$ blend were used as a matrix, owing to the strong interfacial bonding between $\mathrm{SiO}_{2}$ and silicone rubber, the SSPCM exhibits a low leakage rate and high absorption ratio reaching $76.05 \%$. Besides, the introduction of silicone rubber endows the SSPCM with excellent mechanical properties in which the tensile strength reached up to 1.041 $\mathrm{MPa}$. Interestingly, proper combination improves the interaction between matrix and PCMs, the changes in modification of $\mathrm{SiO}_{2}$ could worsen the interaction conversely. ${ }^{[152]}$ The silica modified by -OH groups inhibited the phase change of PEG due to the extremely strong interaction between silica and PEG, which restrained the 
movement of PEG chains in nanochannels and dramatically exacerbated the phase transition. Comparatively, modified by $-\mathrm{NH}_{2}$ weakened the interaction between silica and PEG which facilitates the PEG crystalline, and the corresponding phase change enthalpy increased from $0 \mathrm{~J} / \mathrm{g}$ to $58.76 \mathrm{~J} / \mathrm{g}$. Thereby coupling suitable PCM and matrix is essential.

In a practical application such as novel smart textile, or thermal management, the introduction of polymers especially could be a future direction. ${ }^{[153,154]}$

\section{Energy storage applications}

In the past, studies focusing on SSPCMs to storage energy are mainly concentrating on converting solar energy to thermal energy. Nowadays, growing attention is attracted to other energy conversion categories: (1) electrical-to-thermal conversion, transporting electricity energy into thermal energy which is in the merit of improved conductivity; (2) magneticto-thermal conversion, transporting magnetic energy to thermal energy. The combination of these subjects could lead to novel applications of SSPCMs in the future. Thereby, the below text describes the SSPCMs with solar-to-thermal, electrical-to-thermal, and magnetocaloric energy storage.

\subsection{Solar-to-thermal energy storage}

Sun is a substantial, economical, and green energy source. Nowadays, much effort has been consumed in the development of efficient solar energy harvest, especially in photovoltaics. Nevertheless, the utilization of sunlight is still constrained by the low conversion efficiency and storage method. The SSPCM transforming light into thermal energy has gained plenty of attention.

Typically, the SSPCMs with excellent solar-to-thermal conversion have supporting materials with notable light absorption. In this regard, various dark-color matrices and fillers are introduced into the SSPCMs. Yang et al..$^{[155]}$ adopted graphene oxide (GO) and graphene nanoplatelets (GNPs) hybrid aerogels to impregnate PEG. Except for the initial aiming properties such as high thermal conductivity, energy storage density, excellent shape stabilization, and thermal repeatability, the SSPCM also obtained a 92 5\% light-to-heat conversion efficiency with an addition of $0.45 \mathrm{wt} . \% \mathrm{GO}$ and ca. $1.8 \mathrm{wt} . \%$ GNP. With such low dope of filler, the conversion efficiency is high.

To realize the enhanced light harvest, the supporting materials could be modified with light-harvest materials. Our group modified the MF/MXene supporting matrix with PDA to impregnate PEG, considering that the PDA and MXene were well-known for their high light absorption ability. ${ }^{[156]}$ The results showed the SSPCM maintains excellent solar harvest performance by the energization effect of PDA and MXene (Fig. 15). The method represents a type of approach to enhance the light harvest ability.

Wang and coworkers ${ }^{[157]}$ creatively used organic dyes as light capturers to design an efficient light-harvest PCM for both the conversion and storage of solar energy. The organic phase change material is divided into two functional parts (Fig. 16): (a) dyes, responsible to harvest light; (b) MPEG, mainly constructed by PEG and capable of undertaking absorbed energy during solid-liquid phase change. The PCM achieved a remarkably high solar-to-thermal energy conversion efficiency (94\%). In addition, the material is capable of various adjustments in which many parameters such as phase change temperature, and latent heat could be controlled. The work displayed an entirely new method to design and fabricate the SSPCMs.

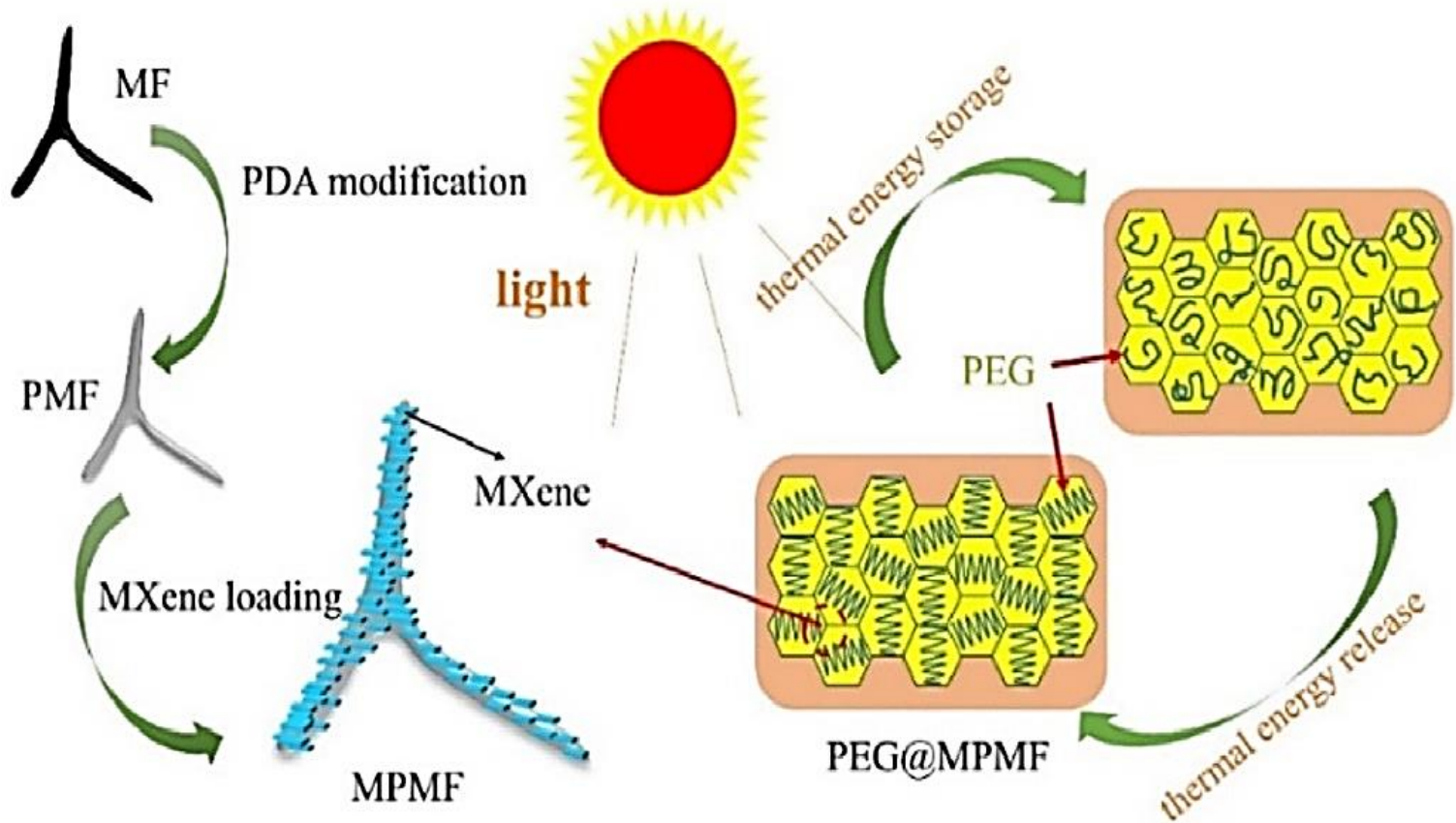

Fig. 15 Illustration of the MXene/PDA-based SSPCMs with the enhanced light harvest. (Reproduced with permission from [156], Copyright 2021 ELSEVIER) 


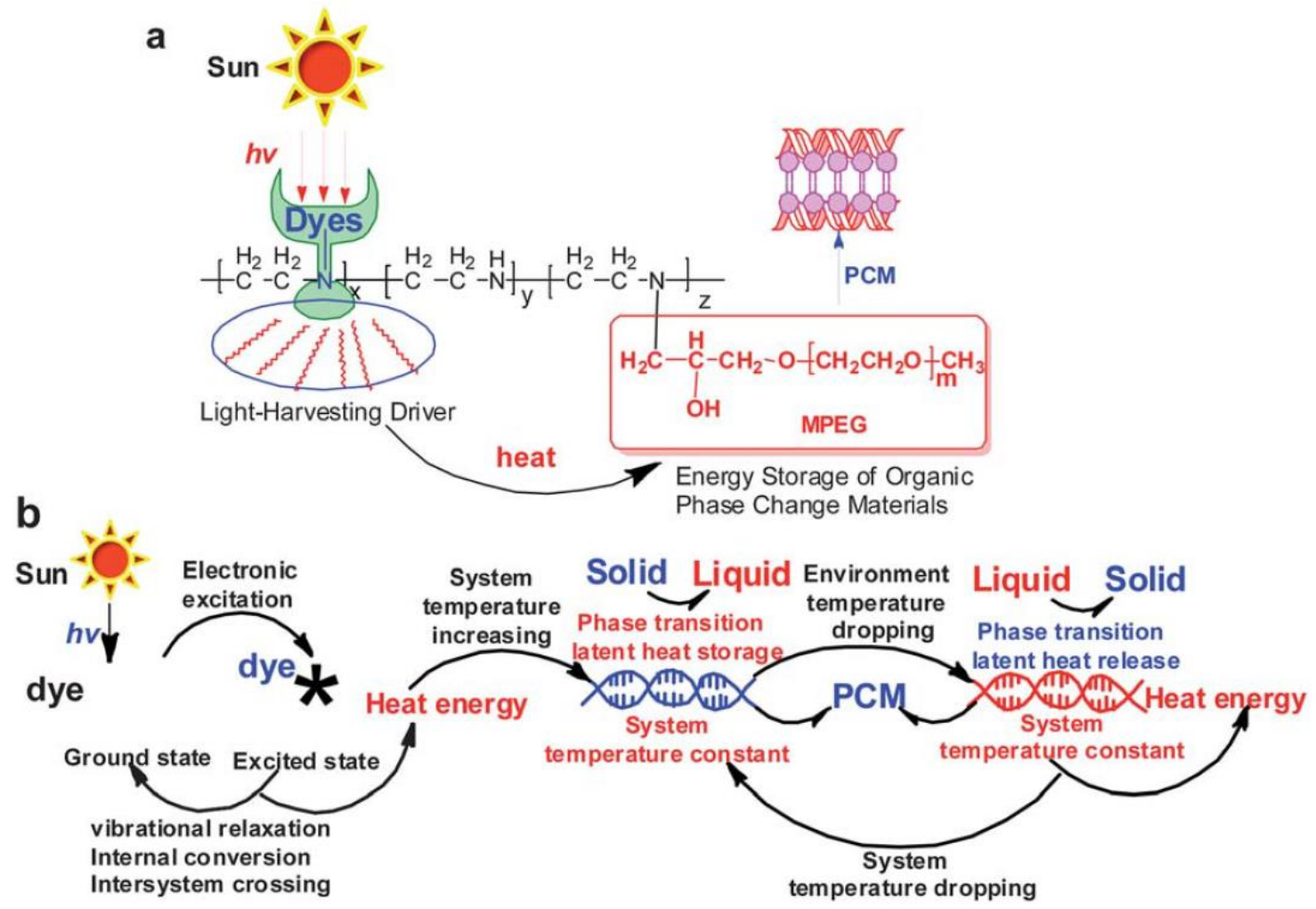

Fig. 16 (a) Chemical structures of solar thermal conversion materials with phase change energy storage. (b) Schematic diagram of light-to-heat conversion and storage. (Reproduced with permission from [157], Copyright 2021 RSC)

\subsection{Electrical-to-thermal energy storage}

As is wildly known, organic PCMs are generally electrically insulated, to obtain composites with electrical-to-thermal conversion ability, the conductive pathway is indispensable. The solution is to impregnate the organic PCMs into highly conductive skeletons which transform the electricity into thermal energy.

In Chen' work, ${ }^{[158]}$ a deformable carbon nanotube sponge was reported to encapsulate PW to obtain tailoredconductivity SSPCMs (Fig. 17a). By changing the fraction of CNT and PW from 2:8 to $1: 9$, the thermal conductivity of SSPCM increased by $40 \%$ and the enhancement of thermal conductivity appears to be saturated. Interestingly, the SSPCM, driven by small voltage, acquired high electro-to-thermal conversion efficiencies, which are $40.6 \%$ under $1.5 \mathrm{~V}$ and $52.5 \%$ under $1.75 \mathrm{~V}$. Additionally, the efficiency of solar energy harvesting ranges from $40 \%$ to $60 \%$ which increased with light intensity. The work constructs a highly conductive nanotube network during both the melting and freezing of PW. What's more, the tailored thermal conductivity endows the material with wilder practical potential.

$\mathrm{Wu}$ and coworkers ${ }^{[159]}$ employed cellulose nanofiber and graphene nanoplatelet to coat melamine foam which was used as a skeleton to impregnate PEG (Fig. 17b). The SSPCM showed great light and electricity-induced shape memory effect attributing to the elasticity of melamine foam and phase change of PEG. Besides, light and electricity could be efficiently transformed into thermal energy and storage by the SSPCM which also obtained excellent multi-responsive self- adhesion properties, exhibiting great potential in various installation and application occasions.

High electric conductivity graphene, is always employed as a supporting material and filler to enhance both thermal conductivity and electric conductivity, which further results in high electro-to-thermal conversion. In Zhou's work [160], HNTs-hybrid graphene aerogel fabricated through facile chemical reduction and air-drying was impregnated with polyurethane to fabricate SSPCMs. Except for excellent thermal stability and reliability, the HNTs-GA skeleton endows the system with considerate light-to-thermal $(\eta=$ $75.6 \%)$ and electro-to-thermal $(\eta=67.2 \%)$ conversion. Besides serving as a skeleton, in Wei's work ${ }^{[161]}$, via a combination of pre-refrigeration and freeze-drying techniques, graphene was reported to be a filler to modify the cellulose matrix. Interestingly, with only $1.51 \mathrm{wt} . \%$ of graphene, high thermal conductivity $(1.03 \mathrm{~W} / \mathrm{m} \mathrm{K})$ was obtained and the SSPCMs display simultaneously light-to-thermal and electroto-thermal behaviors, the study cut down on the usage of graphene which greatly reduces the cost of manufacture.

Novel biomass-derived material, hollow carbon fiber, was reported to encapsulate PW whose fraction could reach up to $85 \%$ by Umir. ${ }^{[162]}$ The developed SSPCM exhibits interconnected electrically conductive pathways in the matrix which results in outstanding energy conversion and storage efficiencies under low input voltage and light. Notably, the electrothermal energy conversion efficiency was significantly high with a value of $81.1 \%$ under $3.0 \mathrm{~V}$ voltage.

The present works already get relatively high electron-to- 


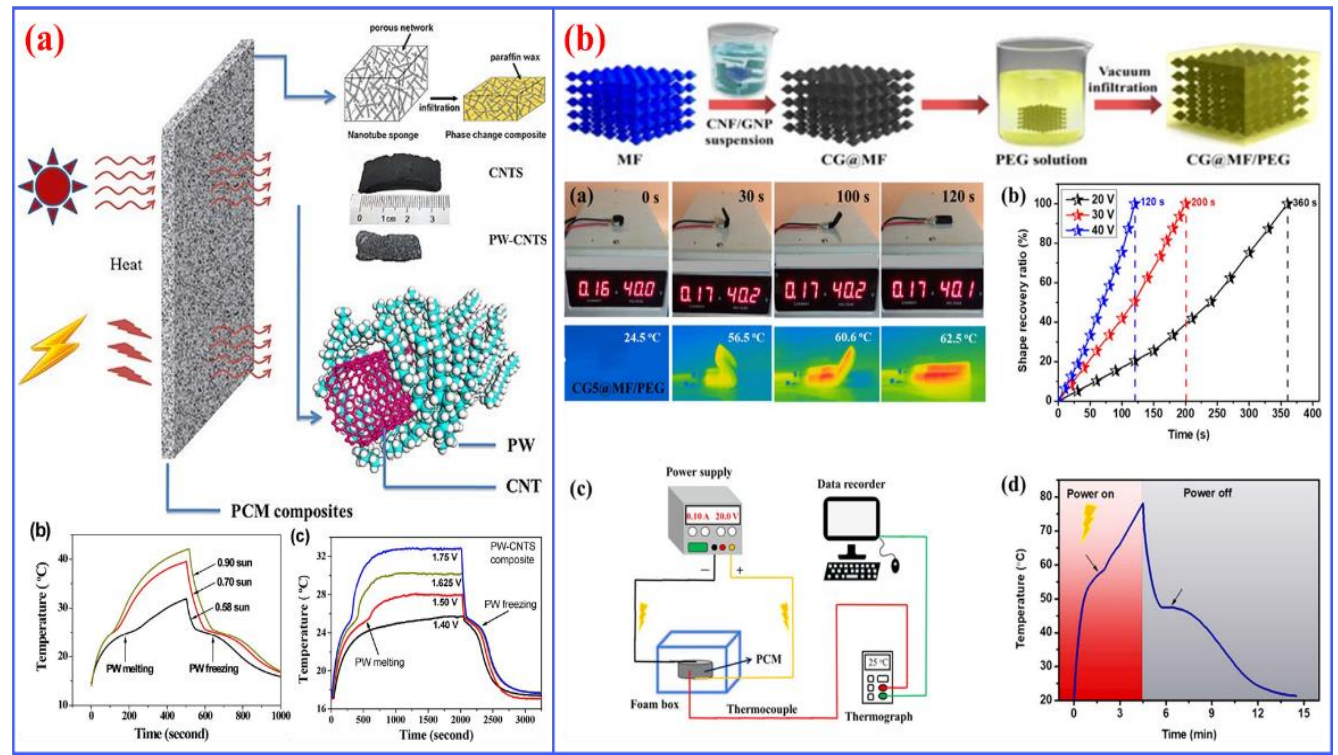

Fig. 17 (a) Illustration of energy storage and structure of PW/CNTs (b) fabrications of CG@MF/PEG and electron-to-thermal conversion. (Reproduced with permission from [158] and [159], Copyright 2021 ACS).

thermal conversion, however, there are only a few works concerning the corresponding practical implements, leaving vast space for future explorations.

\subsection{Magnetic-to-thermal energy storage}

The magnetocaloric material consists of metal, and metal oxide which absorb energy from the magnetic field to transform magnetic energy into thermal energy through $\mathrm{N}^{\prime}$ eel relaxation or Brownian relaxation. ${ }^{[163,164]}$ It has great application in drug delivery ${ }^{[165]}$, thermal therapy ${ }^{[166]}$, both of which are relied on the magnetic-to-thermal energy conversion and storage. However, in existing SSPCMs, The $\mathrm{Fe}_{3} \mathrm{O}_{4}$ is the most popular filler to endow PCMs with magnetic ability attributed to nontoxic and excellent biocompatibility.

Jiang's work ${ }^{[167]}$, designed a type of dual-functional magnetic microcapsules containing a PCM core and an organo-silica shell for the electromagnetic shielding and thermal regulating PI (polyimide) films. The magnetic microcapsules were synthesized through interfacial polycondensation in a reverse emulsion templating system. Zhang's group ${ }^{[168]}$ also design magnetic SSPCMs whose skeleton is poly(MMA-MAA) modified by $\mathrm{Fe}_{3} \mathrm{O}_{4}$ and the working substance is n-octadecane. The SSPCM exhibits high enthalpy of $132 \mathrm{~J} / \mathrm{g}$ with a $20 \mathrm{emu} / \mathrm{g}$ saturation magnetization. A dual-functional SSPCM with thermal energy storage and superparamagnetic nature was developed by microencapsulation in Li's work. ${ }^{[169]}$ The SSPCM has a C20 core that was shelled with $\mathrm{Fe}_{3} \mathrm{O}_{4} / \mathrm{SiO}_{2}$ hybrid material. The SSPCM presents a uniform morphology with 4-6 $\mu \mathrm{m}$ perfect spherical particles. The manufacturing process demonstrates that both energy storage capacity and encapsulation of magnetic shell are determined by C20/TEOS ratio which reveals a novel method to develop magnetic microencapsulated SSPCMs. And resulting of its dual function, the materials have great potential for temperature regulation and anti-radiation, stealth aircraft, anti-jamming coatings, etc.

Tang's group did lots of meaningful work concerning magnetocaloric material. A novel magnetic and sunlightdriven SSPCM was reported to design based on $\mathrm{Fe}_{3} \mathrm{O}_{4}$ and the matrix is a graphene nanosheet (Fig. 18). ${ }^{[170]}$ The developed SSPCM displays high efficiency (41.7\%) of conversion from magnetic energy to thermal energy. Meanwhile, it can absorb storage thermal energy under solar illumination with solar to thermal energy conversion reaching $92.3 \%$. The conductivity is also revealed to have a slight enhancement.

In a $\mathrm{SiO}_{2} / \mathrm{Fe}_{3} \mathrm{O}_{4}$ system, ${ }^{[171]} \mathrm{PEG}$ was used as be working substance. Through sol-the gel method, the synthesized $\mathrm{Fe}_{3} \mathrm{O}_{4} / \mathrm{PEG} / \mathrm{SiO}_{2}$ SSPCM have a high absorption of PEG whose fraction reached $80 \%$, besides, the composites exhibit excellent magnetic-to-thermal effect under an alternating magnetic field.

Thermotherapy is another important application of magnetic-to-thermal energy storage which accumulates heat to kill harmful cells and bacteria. A simple and effective approach for temperature control in magnetic thermotherapy through phase transition is reported. ${ }^{[172]}$ Specifically, extracorporeal magnetic thermotherapy materials are synthesized by introducing superparamagnetic nanoparticles into SSPCM with high-phase transition enthalpy in the thermotherapy temperature range of $41{ }^{\circ} \mathrm{C}-47^{\circ} \mathrm{C}$. The $\mathrm{SiO}_{2} / \mathrm{Fe}_{3} \mathrm{O}_{4}$ system was adopted to absorb TTIPU/PW composites, and the fabricated magnetic thermotherapy materials acquired a high melting enthalpy $\left(>113 \mathrm{~J} \cdot \mathrm{g}^{-1}\right)$ and were able to regulate temperature fluctuation within 41 to $47^{\circ} \mathrm{C}$ under alternating magnetic field. The significance of the work is to reveal an effective way to control the ambient temperature which is important to temperature-sensitive occasions, especially in the human body.

Ghosh ${ }^{[173]}$ developed two kinds of $\mathrm{Fe}_{3} \mathrm{O}_{4}$ magnetic nanoparticles $\left(\mathrm{Fe}_{3} \mathrm{O}_{4} \mathrm{MN}\right)$-based magnetocaloric material by 


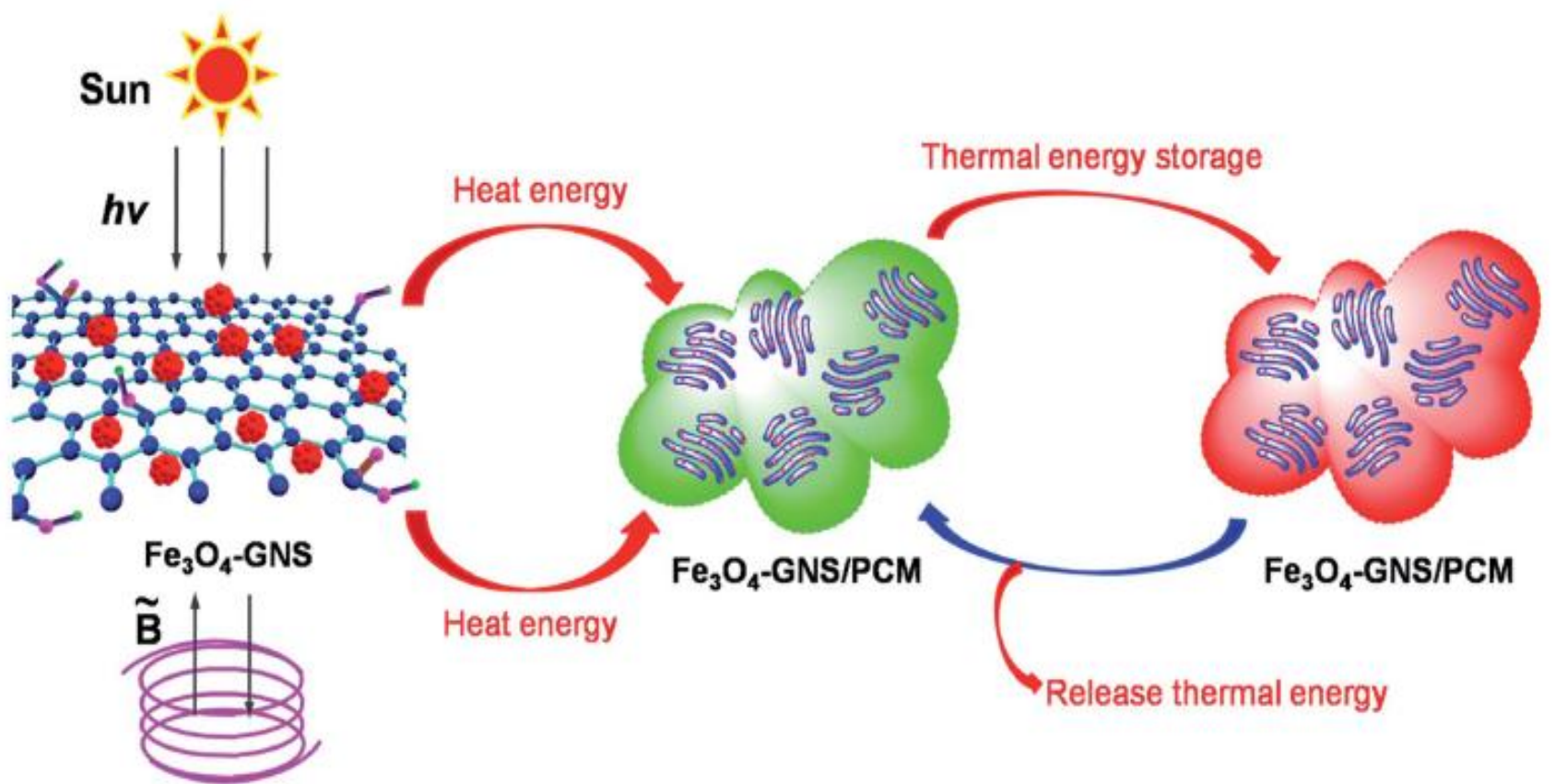

Fig. 18 The magnetic-to-thermal and light-to-thermal energy conversion of $\mathrm{Fe}_{3} \mathrm{O}_{4}-\mathrm{GNS} / \mathrm{SiO}_{2}$. (Reproduced with permission from [170], Copyright 2021 RSC)

a co-precipitation method. The $\mathrm{Fe}_{3} \mathrm{O}_{4}$ is capped with PEG $\left(\mathrm{Fe}_{3} \mathrm{O}_{4}\right.$-PEG-MN) and oleic acid $\left(\mathrm{Fe}_{3} \mathrm{O}_{4}-\mathrm{OA}-\mathrm{MN}\right)$, respectively, which both reduce the aggregation of final magnetic materials. As designed, the magnetic materials show the excellent capability to kill human breast cancer cells. Compared with the control group, $\mathrm{Fe}_{3} \mathrm{O}_{4}-\mathrm{OA}-\mathrm{MN}$ treatment exhibited a $35 \%$ killing rate, and the rate further enhanced to $65 \%$ under heating conditions. Magnetic material shows remarkable improvement in cancer treatment and displays itself as a suitable material for hyperthermia application.

\section{Conclusion and perspective}

Herein, a comprehensive review based on phase change materials focusing on fabrication and energy storage applications has been presented. The desired properties for the PCMs and SSPCMs are firstly summarized to provide a guideline for the fabrications of SSPCMs. Meanwhile, the multiple methods to develop high-performance SSPCMs were discussed, including 3D porous materials absorption, encapsulation, and polymer shaping technology involving all the factors affecting the properties of SSPCMs. Moreover, the energy storages based on SSPCMs from the light, electricity, and magneticity to thermal energy were discussed. Overall, both the fabrications and energy storage applications are witnessed great improvements and widespread utilizations.

Several critical challenges and future research directions are highlighted below. (1) The discovery and development of new PCMs with controlled thermal and chemical properties especially high latent heat. (2) The modification methods and development for high-performance supporting materials on account of the limitation caused by the present supporting materials. (3) The further thermal transfer improvements of
SSPCMs and systematical enhancement mechanisms as well as reduction of interfacial thermal resistance in SSPCMs. (4) High and controlled electron and magnetic-to-thermal conversion. (5) Design and development of advanced multifunctional SSPCMs and their further specific applications.

\section{Acknowledgments}

This work was supported by the National Key Technology R\&D Program of China (Grants 2020YFB1709300) and the Fundamental Research Funds for Central Universities (Grants 2021XXJS035).

\section{Supporting information}

Not Applicable.

\section{Conflict of interest}

There are no conflicts to declare.

\section{References}

[1] S. Chu, A. Majumdar, Nature, 2012, 488, 294-303, doi: 10.1038/nature11475.

[2] S. Chu, Y. Cui, N. Liu, Nature Materials, 2017, 16, 16-22, doi: 10.1038/nmat4834.

[3] I. Gur, K. Sawyer, R. Prasher, Science, 2012, 335, 1454-1455, doi: 10.1126/science.1218761.

[4] L. E. Bell, Science, 2008, 321, 1457-1461, doi: 10.1126/science. 1158899 .

[5] S. Koohi, M. A. Rosen, Journal of Energy Storage, 2020, 27, 101047, doi: 10.1016/j.est.2019.101047.

[6] X. Lu, B. Liang, X. Sheng, T. Yuan, J. Qu, Solar Energy Materials and Solar Cells, 2020, 208, 110391, doi: 
10.1016/j.solmat.2019.110391.

[7] H. Peng, J. Wang, X. Zhang, J. Ma, T. Shen, S. Li, B. Dong, Applied Thermal Engineering, 2021, 185, 116326, doi: 10.1016/j.applthermaleng.2020.116326.

[8] M. C. Ndukwu, L. Bennamoun, M. Simo-Tagne, Energies, 2021, 14, 724, doi: 10.3390/en14030724.

[9] X. Yuan, X. Zhou, Y. Pan, R. Kosonen, H Cai, Y. Gao, Y. Wang, Energy and Buildings, 2021, 236, 110764, doi: 10.1016/j.enbuild.2021.110764.

[10] J. Shi, X. Huang, H. Guo, X. Shan, Z. Xu, X. Zhao, Z. Sun, W. Aftab, C. Qu, R. Yao, R. Zou, ES Energy \& Environment, 2020 , 8, 21-28, doi: 10.30919/esee8c380.

[11] R. Hu, Y. Liu, S. Shin, S. Huang, X. Ren, W. Shu, J. Cheng, G. Tao, W. Xu, R. Chen, X. Luo, Advanced Energy Materials, 2020, 10, 1903921, doi: 10.1002/aenm.201903921.

[12] S. Zhang, D. Feng, L. Shi, L. Wang, Y. Jin, L. Tian, Z. Li, G. Wang, L. Zhao, Y. Yan, Renewable and Sustainable Energy Reviews, 2021, 135, 110127, doi: 10.1016/j.rser.2020.110127.

[13] N. Zhang, Y. Yuan, X. Cao, Y. Du, Z. Zhang, Y. Gui, Advanced Engineering Materials, 2018, 20, 201700753, doi: 10.1002/adem.201700753.

[14] W. Tao, Y. Zhang, X. Kong, W. Zhang, C. Fan, The Chinese Journal of Process Engineering, 2020, 20, 619-627.

[15] D. G. Prajapati, B. Kandasubramanian, Industrial \& Engineering Chemistry Research, 2019, 58, 10652-10677, doi: 10.1021/acs.iecr.9b01693.

[16] X. Lu, H. Liu, V. Murugadoss, I. Seok, J. Huang, J.E. Ryu, Z. Guo, Engineered Science, 2020, 9, 25-34, doi: $10.30919 / \mathrm{es} 8 \mathrm{~d} 901$.

[17] J. Huang, Y. Luo, M. Weng, J. Yu, L. Sun, H. Zeng, Y. Liu, W. Zeng, Y. Min, Z. Guo, ES Materials and Manufacturing, 2021, 13, 23-39, doi: 10.30919/esmm5f458.

[18] Y. Zhang, M. M. Umair, S. Zhang, B. Tang, Journal of Materials Chemistry A, 2019, 7, 22218-22228, doi: $10.1039 / \mathrm{c} 9 \mathrm{ta} 06678 \mathrm{k}$.

[19] X. Lin, X. Zhang, J. Ji, L. Zheng, International Journal of Energy Research, 2021, 45, 9831-9857, doi: 10.1002/er.6538.

[20] Y. Zhou, S. Wu, Y. Ma, H. Zang, X. Zeng, F. Wu, F. Liu, J. E. Ryu, Z. Guo, ES Energy \& Environment, 2020, 9, 28-40, doi: 10.30919/esee8c150.

[21] U. B. Shahid, A. Abdala, Energy Storage Materials, 2021, 34, 365-387, doi: 10.1016/j.ensm.2020.10.004.

[22] K. Yuan, J. Shi, W. Aftab, M. Qin, A. Usman, F. Zhou, Y. Lv, S. Gao, R. Zou, Advanced Functional Materials, 2020, 30, 1904228, doi: 10.1002/adfm.201904228.

[23] T. Khadiran, M. Z. Hussein, Z. Zainal, R. Rusli, Solar Energy Materials and Solar Cells, 2015, 143, 78-98, doi: 10.1016/j.solmat.2015.06.039.

[24] K. Faraj, M. Khaled, J. Faraj, F. Hachem, C. Castelain, Renewable and Sustainable Energy Reviews, 2020, 119, 109579, doi: 10.1016/j.rser.2019.109579.

[25] B. Liu, X. Zhang, J. Ji, International Journal of Energy Research, 2021, 1-23, doi: 10.1002/er.6397.

[26] K. Du, J. Calautit, P. Eames, Y. Wu, Renewable Energy, 2021 168, 1040-1057, doi: 10.1016/j.renene.2020.12.057.
[27] S. Seitz, H. Ajiro, Solar Energy Materials and Solar Cells, 2019, 190, 57-64, doi: 10.1016/j.solmat.2018.10.012.

[28] J. Weng, D. Ouyang, X. Yang, M. Chen, G. Zhang, J. Wang, Applied Thermal Engineering, 2020, 167, 114698, doi: 10.1016/j.applthermaleng.2019.114698.

[29] M. M. Kenisarin, Solar Energy, 2014, 107, 553-575, doi: 10.1016/j.solener.2014.05.001.

[30] R. Gulfam, P. Zhang, Z. Meng, Applied Energy, 2019, 238, 582-611, doi: 10.1016/j.apenergy.2019.01.114.

[31] Y. E. Milián, A. Gutiérrez, M. Grágeda, S. Ushak, Renewable and Sustainable Energy Reviews, 2017, 73, 983-999, doi: 10.1016/j.rser.2017.01.159.

[32] S. Wang, P. Qin, X. Fang, Z. Zhang, S. Wang, X. Liu, Solar Energy, 2014, 99, 283-290, doi: 10.1016/j.solener.2013.11.018.

[33] S. Sundararajan, A. B. Samui, P. S. Kulkarni, Journal of Materials Chemistry A, 2017, 5, 18379-18396, doi: $10.1039 / \mathrm{c} 7 \mathrm{ta} 04968 \mathrm{~d}$.

[34] T. Chen, H. Sun, P. Mu, Z. Zhu, J. An, W. Liang, A. Li, Solar Energy Materials and Solar Cells, 2020, 206, 110340, doi: 10.1016/j.solmat.2019.110340.

[35] T. Chen, C. Liu, P. Mu, H. Sun, Z. Zhu, W. Liang, A. Li, Chemical Engineering Journal, 2020, 382, 122831, doi: 10.1016/j.cej.2019.122831.

[36] L. Wang, D. Meng, Applied Energy, 2010, 87, 2660-2665, doi: 10.1016/j.apenergy.2010.01.010.

[37] X. Lu, J. Huang, B. Kang, T. Yuan, J. P. Qu, Solar Energy Materials and Solar Cells, 2019, 192, 170-178, doi: 10.1016/j.solmat.2018.12.036.

[38] K. Matuszek, R. Vijayaraghavan, C. M. Forsyth, S. Mahadevan, M. Kar, D. R. MacFarlane, ChemSusChem, 2020, 13 159-164, doi: 10.1002/cssc.201902601.

[39] B. Eanest Jebasingh, A. Valan Arasu, Energy Storage Materials, 2020, 24, 52-74, doi: 10.1016/j.ensm.2019.07.031.

[40] X. Sheng, D. Dong, X. Lu, L. Zhang, Y. Chen, Composites Part A: Applied Science and Manufacturing, 2020, 138, 106067, doi: 10.1016/j.compositesa.2020.106067.

[41] H. Zheng, C. Wang, Q. Liu, Z. Tian, X. Fan, Energy Conversion and Management, 2018, 157, 372-381, doi: 10.1016/j.enconman.2017.12.023.

[42] X. Xiao, P. Zhang, M. Li, Applied Energy, 2013, 112, $1357-$ 1366, doi: 10.1016/j.apenergy.2013.04.050.

[43] M. Pan, W. Lai, Renewable Energy, 2017, 114, 408-422, doi: 10.1016/j.renene.2017.07.004.

[44] M. Cao, J. H. Huang, Z. Q. Liu, Advances in Materials Science and Engineering, 2020, 2020, 8167384, doi: 10.1155/2020/8167386.

[45] Y. Li, J. Li, Y. Deng, W. Guan, X. Wang, T. Qian, Applied Energy, 2016, 171, 37-45, doi: 10.1016/j.apenergy.2016.03.010.

[46] B. Jiang, X. Wang, D. Wu, Applied Energy, 2017, 201, 2033, doi: 10.1016/j.apenergy.2017.05.093.

[47] L. Zhao, C. Zhong, Y. Wang, S. Wang, B. Dong, L. Wan, Journal of Power Sources, 2015, 292, 49-57, doi: 10.1016/j.jpowsour.2015.05.017.

[48] Y. Zhao, W. Kong, Z. Jin, Y. Fu, W. Wang, Y. Zhang, J. Liu, B. Zhang, Applied Energy, 2018, 222, 180-188, doi: 
10.1016/j.apenergy.2018.04.013.

[49] S. Zhu, T. Ji, D. Niu, Z. Yang, RSC Advances, 2020, 10 44903-44911, doi: 10.1039/d0ra08398d.

[50] P. P. Bag, G. P. Singh, S. Singha, G. Roymahapatra, Engineered Science, 2020, 13, 1-10, doi: 10.30919/es8d1166.

[51] Y. Luan, M. Yang, Q. Ma, Y. Qi, H. Gao, Z. Wu, G. Wang, Journal of Materials Chemistry A, 2016, 4, 7641-7649, doi: 10.1039/c6ta01676f.

[52] X. Meng, L. Meng, J. Zou, F. He, Case Studies in Thermal Engineering, 2021, 23, 100810, doi: 10.1016/j.csite.2020.100810. [53] C. Nie, J. Liu, S. Deng, International Journal of Heat and Mass Transfer, 2021, 165, 120652, doi: 10.1016/j.ijheatmasstransfer.2020.120652.

[54] M. Inagaki, Y. Kaburagi, Y. Hishiyama, Advanced Engineering Materials, 2014, 16, 494-506, doi: 10.1002/adem.201300418.

[55] I. Kholmanov, J. Kim, E. Ou, R. S. Ruoff, L. Shi, ACS Nano, 2015, 9, 11699-11707, doi: 10.1021/acsnano.5b02917.

[56] Y. Zhao, M. Niu, F. Yang, Y. Jia, Y. Cheng, Engineered Science, 2019, 8, 33-38, doi: 10.30919/es8d501.

[57] C. Li, B. Zhang, Q. Liu, Journal of Energy Storage, 2020, 29, 101339, doi: 10.1016/j.est.2020.101339.

[58] H. Yin, S. Gao, C. Liao, C. Li, Z. Cai, Y. Xu, J. Liu, Journal of Cleaner Production, 2019, 235, 359-368, doi: 10.1016/j.jclepro.2019.06.355.

[59] M. Luo, J. Song, Z. Ling, Z. Zhang, X. Fang, Materials Today Energy, 2021, 20, 100652, doi: 10.1016/j.mtener.2021.100652.

[60] S. Wu, T. Li, Z. Tong, J. Chao, T. Zhai, J. Xu, T. Yan, M. Wu, Z. Xu, H. Bao, T. Deng, R. Wang, Advanced Materials, 2019, 31, 1905099, doi: 10.1002/adma.201905099.

[61] X. Chen, H. Gao, G. Hai, D. Jia, L. Xing, S. Chen, P. Cheng, M. Han, W. Dong, G. Wang, Energy Storage Materials, 2020, 26, 129-137, doi: 10.1016/j.ensm.2019.12.029.

[62] P.-C. Ma, S.-Y. Mo, B.-Z. Tang, J.-K. Kim, Carbon, 2010, 48, 1824-1834, doi: 10.1016/j.carbon.2010.01.028.

[63] J. Wang, H. Xie, Z. Xin, Thermochimica Acta, 2009, 488, 39-42, doi: 10.1016/j.tca.2009.01.022.

[64] J. Wang, H. Xie, Z. Xin, Journal of Materials Science \& Technology, 2011, 27, 233-238, doi: 10.1016/s10050302(11)60055-8.

[65] M. Li, M. Chen, Z. Wu, J. Liu, Energy Conversion and Management, 2014, $\quad \mathbf{8 3}, \quad 325-329, \quad$ doi: 10.1016/j.enconman.2014.04.002.

[66] R. Cao, S. Chen, Y. Wang, N. Han, H. Liu, X. Zhang, Carbon 2019, 149, 263-272, doi: 10.1016/j.carbon.2019.04.005.

[67] Z. Liu, R. Zou, Z. Lin, X. Gui, R. Chen, J. Lin, Y. Shang, A. Cao, Nano Letters, 2013, 13, 4028-4035, doi: 10.1021/nl401097d. [68] T. Qian, S. Zhu, H. Wang, A. Li, B. Fan, ACS Sustainable Chemistry \& Engineering, 2019, 7, 2446-2458, doi: 10.1021/acssuschemeng.8b05335.

[69] H. Song, J. Liu, B. Liu, J. Wu, H. M. Cheng, F. Kang, Joule, 2018, 2, 442-463, doi: 10.1016/j.joule.2018.01.006.

[70] C. Liu, M. Chen, W. Yu, Y. He, ES Energy Environment, 2018, 2, 31-42, doi: 10.30919/esee8c191.
[71] K. Sun, Y. Kou, H. Dong, S. Ye, D. Zhao, J. Liu, Q. Shi, Journal of Materials Chemistry A, 2021, 9, 1213-1220, doi: 10.1039/d0ta09035b.

[72] M. Li, B. Mu, Applied Energy, 2019, 242, 695-715, doi: 10.1016/j.apenergy.2019.03.085.

[73] J. Mao, J. Iocozzia, J. Huang, K. Meng, Y. Lai, Z. Lin, Energy \& Environmental Science, 2018, 11, 772-799, doi: 10.1039/c7ee03031b.

[74] H. Ji, D. P. Sellan, M. T. Pettes, X. Kong, J. Ji, L. Shi, R. S. Ruoff, Energy \& Environmental Science, 2014, 7, 1185-1192, doi: $10.1039 / \mathrm{c} 3$ ee42573h.

[75] W. Dan, W. Chunxian, J. Gan, S. Xinxin, X. Yuhui, Solar Energy Materials and Solar Cells, 2021, 224, 111013. dio: 10.1016/j.solmat.2021.111013.

[76] H. Liao, W. Chen, Y. Liu, Q. Wang, Composites Science and Technology, 2020, 189, 108010, doi: 10.1016/j.compscitech.2020.108010.

[77] B. Tian, W. Yang, F. He, C. Xie, K. Zhang, J. Fan, J. Wu, Fullerenes, Nanotubes and Carbon Nanostructures, 2017, 25, 512-518, doi: 10.1080/1536383x.2017.1347638.

[78] Z. Wang, X. Shen, M. Akbari Garakani, X. Lin, Y. Wu, X. Liu, X. Sun, J. K. Kim, ACS Applied Materials \& Interfaces, 2015, 7, 5538-5549, doi: 10.1021/acsami.5b00146.

[79] L. Ma, Q. Wang, L. Li, Solar Energy Materials and Solar Cells, 2019, 194, 215-221, doi: 10.1016/j.solmat.2019.02.026.

[80] Y. Xie, W. Li, H. Huang, D. Dong, X. Zhang, L. Zhang, Y. Chen, X. Sheng, X. Lu, ACS Sustainable Chemistry \& Engineering, 2020, 8, 8448-8457, doi: 10.1021/acssuschemeng.0c02959.

[81] D. G. Atinafu, S. Wi, B. Y. Yun, S. Kim, Energy, 2021, 216, 119294, doi: 10.1016/j.energy.2020.119294.

[82] X. Hu, H. Huang, Y. Hu, X. Lu, Y. Qin, Solar Energy Materials and Solar Cells, 2021, 219, 110790, doi: 10.1016/j.solmat.2020.110790.

[83] Z. Qiu, S. Wang, Y. Wang, J. Li, Z. Xiao, H. Wang, D. Liang, Y. Xie, Composites Science and Technology, 2020, 200, 108407, doi: 10.1016/j.compscitech.2020.108407.

[84] R. Wen, X. Zhang, Z. Huang, M. Fang, Y. Liu, X. Wu, X. Min, W. Gao, S. Huang, Solar Energy Materials and Solar Cells, 2018, 178, 273-279, doi: 10.1016/j.solmat.2018.01.032.

[85] X. Gu, P. Liu, C. Liu, L. Peng, H. He, Materials Letters, 2019, 248, 12-15, doi: 10.1016/j.matlet.2019.03.130.

[86] B. Wu, S. Lyu, H. Han, T. Li, H. Sun, J.-K. Wang, D. Li, F. Lei, J. Huang, D. Sun, Composites Part B: Engineering, 2021, 205, 108500, doi: 10.1016/j.compositesb.2020.108500.

[87] Y. Li, X. Huang, Y. Li, Z. Xi, G. Hai, Z. Tao, G. Wang, Sustainable Energy \& Fuels, 2020, 4, 1764-1772, doi: 10.1039/c9se01272a.

[88] C. Liu, Q. Fang, D. Wang, C. Yan, F. Liu, N. Wang, Z. Guo, Q. Jiang, ES Materials \& Manufacturing, 2019, 3, 2-15, doi: 10.30919/esmm5f199.

[89] Z. Qian, H. Shen, X. Fang, L. Fan, N. Zhao, J. Xu, Energy and Buildings, 2018, 158, 1184-1188, doi: 10.1016/j.enbuild.2017.11.033.

[90] J. Yang, G. Q. Qi, L. S. Tang, R. Y. Bao, L. Bai, Z. Y. Liu, W. 
Yang, B. H. Xie, M. B. Yang, Journal of Materials Chemistry A, 2016, 4, 9625-9634, doi: 10.1039/c6ta03733j.

[91] B. Wang, G. Li, L. Xu, J. Liao, X. Zhang, ACS Nano, 2020, 14, 16590-16599, doi: 10.1021/acsnano.0c05931.

[92] J. Wie, J. Kim, Polymers, 2021, 13, 13030456, doi: 10.3390/polym13030456.

[93] X. Jia, Q. Li, C. Ao, R. Hu, T. Xia, Z. Xue, Q. Wang, X. Deng, W. Zhang, C. Lu, Composites Part A: Applied Science and Manufacturing, 2020, 129, 105710, doi: 10.1016/j.compositesa.2019.105710.

[94] X. Chen, Z. Tang, H. Gao, S. Chen, G. Wang, Science, 2020, 23, 101208, doi: 10.1016/j.isci.2020.101208.

[95] P. Lin, J. Xie, Y. He, X. Lu, W. Li, J. Fang, S. Yan, L. Zhang, X. Sheng, Y. Chen, Solar Energy Materials and Solar Cells, 2020, 206, 110229, doi: 10.1016/j.solmat.2019.110229.

[96] X. Lu, H. Huang, X. Zhang, P. Lin, J. Huang, X. Sheng, L. Zhang, J.-P. Qu, Composites Part B: Engineering, 2019, 177, 107372, doi: 10.1016/j.compositesb.2019.107372.

[97] N. Aslfattahi, R. Saidur, A. Arifutzzaman, R. Sadri, N. Bimbo, M. F. M. Sabri, P. A. Maughan, L. Bouscarrat, R. J. Dawson, S. M. Said, B. T. Goh, N. A. C. Sidik, Journal of Energy Storage, 2020, 27, 101115, doi: 10.1016/j.est.2019.101115.

[98] L. Tang, X. Zhao, C. Feng, L. Bai, J. Yang, R. Bao, Z. Liu, M. Yang, W. Yang, Solar Energy Materials and Solar Cells, 2019, 203, 110174, doi: 10.1016/j.solmat.2019.110174.

[99] L. Vertuccio, F. Foglia, R. Pantani, M. D. R. Sánchez, B. Calderón, L. Guadagno, Composites Part B: Engineering, 2021, 207, 108583, doi: 10.1016/j.compositesb.2020.108583.

[100] X. Huang, C. Zhi, P. Jiang, The Journal of Physical Chemistry C, 2012, 116, 23812-23820, doi: 10.1021/jp308556r.

[101] A. Yu, P. Ramesh, X. Sun, E. Bekyarova, M. E. Itkis, R. C. Haddon, Advanced Materials, 2008, 20, 4740-4744, doi: 10.1002/adma.200800401.

[102] J. Huang, B. Zhang, M. He, X. Huang, G. Wu, G. Yin, Y. Cui, Journal of Materials Science, 2020, 55, 7337-7350, doi: 10.1007/s10853-020-04514-9.

[103] W. Sliwka, Microencapsulation, Angewandte Chemie International Edition in English, 1975, 14, 539-550, doi: 10.1002/anie. 197505391.

[104] K. B. Green, Carbonless paper production, 1953.

[105] G. Niu, W. Li, F. Meng, L. Wang, H. Dong, Y. Qiu, Journal of Materials Chemistry A, 2014, 2, 705-710, doi: 10.1039/c3ta13606j.

[106] Y. Han, S. Meyer, Y. Dkhissi, K. Weber, J. M. Pringle, U. Bach, L. Spiccia, Y. B. Cheng, Journal of Materials Chemistry A, 2015, 3, 8139-8147, doi: 10.1039/c5ta00358j.

[107] A. Singh, G. van den Mooter, Advanced Drug Delivery Reviews, 2016, 100, 27-50, doi: 10.1016/j.addr.2015.12.010.

[108] A. Ziaee, A. B. Albadarin, L. Padrela, T. Femmer, E. O'Reilly, G. Walker, European Journal of Pharmaceutical Sciences, 2019, 127, 300-318, doi: 10.1016/j.ejps.2018.10.026.

[109] M. Davis, G. Walker, Journal of Controlled Release, 2018, 269, 110-127, doi: 10.1016/j.jconrel.2017.11.005.

[110] A. T. Ogunjimi, J. Fiegel, N. K. Brogden, Pharmaceutics, 2020, 12, 12060496, doi: 10.3390/pharmaceutics12060496.
[111] K. G. H. Desai, H. Jin Park, Drying Technology, 2005, 23, 1361-1394, doi: 10.1081/drt-200063478.

[112] J. M. Obón, M. R. Castellar, M. Alacid, J. A. FernándezLópez, Journal of Food Engineering, 2009, 90, 471-479, doi: 10.1016/j.jfoodeng.2008.07.013.

[113] R. H. Snow, 2003, Spray Dryers, A guide to performance evaluation. American Institute of Chemical Engineers.

[114] C. Land, Industrial drying equipment, Drying Technology, 1992, 10, 807-808, doi: 10.1080/07373939208916479.

[115] A. M. Borreguero, J. L. Valverde, J. F. Rodríguez, A. H. Barber, J. J. Cubillo, M. Carmona Chemical Engineering Journal, 2011, 166, 384-390, doi: 10.1016/j.cej.2010.10.055.

[116] A. M. Borreguero, A. Serrano, I. Garrido, J. F. Rodríguez, M. Carmona, Energy Conversion and Management, 2014, 87, 138-144, doi: 10.1016/j.enconman.2014.07.027.

[117] A. Nizori, L. T. T. Bui, F. Jie, D. M. Small, Journal of the Science of Food and Agriculture, 2020, 100, 4165-4171, doi: 10.1002/jsfa.10455.

[118] P. Chaiyasat, M. Z. Islam, A. Chaiyasat, RSC Advances, 2013, 3, 10202, doi: 10.1039/c3ra40802g.

[119] F. Shahidi, X. Q. Han, Critical Reviews in Food Science \& Nutrition, 1993, 33, 501-547, doi: 10.1080/10408399309527645. [120] M. Schoebitz, M. D. López, A. Roldán, Agronomy for Sustainable Development, 2013, 33, 751-765, doi: 10.1007/s13593-013-0142-0.

[121] F. Calegari, B. C. da Silva, J. Tedim, M. G. S. Ferreira, M. A. C. Berton, C. E. B. Marino, Progress in Organic Coatings, 2020, 138, 105329, doi: 10.1016/j.porgcoat.2019.105329.

[122] F. Pitié, C. Y. Zhao, J. Baeyens, J. Degrève, H. L. Zhang, Applied Energy, 2013, 109, 505-513, doi: 10.1016/j.apenergy.2012.12.048.

[123] M. A. Izquierdo-Barrientos, C. Sobrino, J. A. AlmendrosIbáñez, Applied Thermal Engineering, 2015, 78, 373-379, doi: 10.1016/j.applthermaleng.2014.12.044.

[124] M. A. Izquierdo-Barrientos, C. Sobrino, J. A. AlmendrosIbáñez, C. Barreneche, N. Ellis, L. F. Cabeza, Applied Energy, 2016, 181, 310-321, doi: 10.1016/j.apenergy.2016.08.081.

[125] M. A. Izquierdo-Barrientos, C. Sobrino, J. A. AlmendrosIbáñez, Journal of Heat Transfer, 2016, 138, 072001, doi: 10.1115/1.4032981.

[126] M. A. Izquierdo, C. Sobrino, J. A. Almendros, Chemical Engineering Journal, 2015, 264, 497-505, doi: 10.1016/j.cej.2014.11.107.

[127] R. C. Brown, J. D. Rasberry, S. P. Overmann, Powder Technology, 1998, 98, 217-222, doi: 10.1016/s00325910(98)00080-1.

[128] S. Ushak, M. Judith Cruz, L. F. Cabeza, M. Gradeda, Materials, 2016, 9, 9010024, doi: 10.3390/ma9010024.

[129] B. B. Paulo, K. Andreola, O. Taranto, A. D. Ferreira, A. S. Prata, Powder Technology, 2019, 341, 147-156, doi: 10.1016/j.powtec.2018.03.003.

[130] M. A. Izquierdo, C. Sobrino, J. A. Almendros, Chemical Engineering Journal, 2013, 230, 573-583, doi: 10.1016/j.cej.2013.06.112.

[131] Q. Zhao, F. He, Q. Zhang, J. Fan, R. He, K. Zhang, H. Yan, 
W. Yang, Solar Energy Materials and Solar Cells, 2019, 203, 110204, doi: 10.1016/j.solmat.2019.110204.

[132] Z. Liu, Z. Chen, F. Yu, Solar Energy Materials and Solar Cells, 2019, 192, 72-80, doi: 10.1016/j.solmat.2018.12.014.

[133] L. Weinstock, R. A. Sanguramath, M. S. Silverstein, Polymer Chemistry, 2019, 10, 1498-1507, doi: 10.1039/c8py01733f.

[134] T. Zhang, Z. Xu, H. Chi, Y. Zhao, ACS Applied Polymer Materials, 2020, 2, 2578-2585, doi: 10.1021/acsapm.0c00223.

[135] R. Kurniawan, A. Sumarlan, D. R. Adhika, Nugraha, AIP Conference Proceedings, 2019, 2088, doi: 10.1063/1.5095353.

[136] X. Du, S. Wang, Z. Du, X. Cheng, H. Wang, Journal of Materials Chemistry $A, \quad 2018, \quad 6, \quad 17519-17529$, doi: $10.1039 / \mathrm{c} 8 \mathrm{ta} 07086 \mathrm{e}$.

[137] R. Jiang, L. Xu, N. Wu, Materials Research Express, 2020 , 7, 095501, doi: 10.1088/2053-1591/abb2cc.

[138] M. Zhao, X. Zhang, X. Kong, Renewable Energy, 2020, 147, 374-383, doi: 10.1016/j.renene.2019.08.117.

[139] D. Hu, Z. Wang, W. Ma, Progress in Organic Coatings, 2021, 151, 106006, doi: 10.1016/j.porgcoat.2020.106006.

[140] X. Zhu, X. Li, J. Shen, B. Wang, Z. Mao, H. Xu, X. Feng, X. Sui, Energy Conversion and Management, 2020, 223, 113478 , doi: 10.1016/j.enconman.2020.113478.

[141] Z. Chen, L. Cao, F. Shan, G. Fang, Energy and Buildings, 2013, 62, 469-474, doi: 10.1016/j.enbuild.2013.03.025.

[142] L. Chai, X. Wang, D. Wu, Applied Energy, 2015, 138, 661674, doi: 10.1016/j.apenergy.2014.11.006.

[143] S. Phadungphatthanakoon, S. Poompradub, S. P. Wanichwecharungruang, ACS Applied Materials \& Interfaces, 2011, 3, 3691-3696, doi: 10.1021/am200870e.

[144] M. Mu, P. A. M. Basheer, W. Sha, Y. Bai, T. McNally, Applied Energy, 2016, 162, 68-82, doi: 10.1016/j.apenergy.2015.10.030.

[145] Y. Lv, X. Yang, X. Li, G. Zhang, Z. Wang, C. Yang, Applied Energy, 2016, 178, 376-382,

10.1016/j.apenergy.2016.06.058.

[146] Y. Hu, X. Song, Q. Zheng, J. Wang, J. Pei, RSC Advances, 2019, 9, 9962-9967, doi: 10.1039/c9ra00874h.

[147] C. G. Guo, Y. Miao, L. P. Li, Journal of Renewable and Sustainable Energy, 2018, 10, 064102, doi: 10.1063/1.5055262.

[148] M. Poikelispää, S. Ruokangas, M. Honkanen, M. Vippola, E. Sarlin, Rubber Chemistry and Technology, 2020, 93, 208-221, doi: $10.5254 /$ rct.19.81468.

[149] X. Lu, H. Yu, L. Zhang, Y. Zheng, L. Xu, Y. Zhao, Energy \& Fuels, 2020, 34, 9020-9029, doi: 10.1021/acs.energyfuels.0c01800.

[150] Y. Chen, S. Gao, C. Liu, S. Yue, J. Liu, H. Huang, Solar Energy Materials and Solar Cells, 2019, 200, 109988, doi: 10.1016/j.solmat.2019.109988.

[151] Y. Guo, W. Yang, Z. Jiang, F. He, K. Zhang, R. He, J. Wu, J. Fan, Solar Energy Materials and Solar Cells, 2019, 196, 16-24, doi: 10.1016/j.solmat.2019.03.034.

[152] D. Feng, Y. Feng, P. Li, Y. Zang, C. Wang, X. Zhang, Microporous and Mesoporous Materials, 2020, 292, 109756, doi: 10.1016/j.micromeso.2019.109756.
[153] Y. Lu, X. Xiao, J. Fu, C. Huan, S. Qi, Y. Zhan, Y. Zhu, G. Xu, Chemical Engineering Journal, 2019, 355, 532-539, doi: 10.1016/j.cej.2018.08.189.

[154] E. Pakdel, M. Naebe, L. Sun, X. Wang, ACS Applied Materials \& Interfaces, 2019, 11, 13039-13057, doi: 10.1021/acsami.8b19067.

[155] J. Yang, G. Q. Qi, Y. Liu, R. Y. Bao, Z. Y. Liu, W. Yang, B. H. Xie, M. B. Yang, Carbon, 2016, 100, 693-702, doi: 10.1016/j.carbon.2016.01.063.

oo[156] D. Yu, H. Haowei, H. Xinpeng, S. Liu, X. Sheng, X. Li, X. Lu, J. Qu, Renewable Energy, 2021, 171, 1-10, doi: 10.1016/j.renene.2021.02.077.

[157] Y. Wang, B. Tang, S. Zhang, Journal of Materials Chemistry, 2012, 22, 18145, doi: 10.1039/c2jm33289b.

[158] L. Chen, R. Zou, W. Xia, Z. Liu, Y. Shang, J. Zhu, Y. Wang, J. Lin, D. Xia, A. Cao, ACS Nano, 2012, 6, 10884-10892, doi: 10.1021/nn304310n.

[159] H. Wu, S. Deng, Y. Shao, J. Yang, X. Qi, Y. Wang, ACS Applied Materials \& Interfaces, 2019, 11, 46851-46863, doi: 10.1021/acsami.9b16612.

[160] Y. Zhou, X. Wang, X. Liu, D. Sheng, F. Ji, L. Dong, S. Xu, H. Wu, Y. Yang, Carbon, 2019, 142, 558-566, doi: 10.1016/j.carbon.2018.10.083.

[161] X. Wei, F. Xue, X. D. Qi, J. H. Yang, Z. W. Zhou, Y. P. Yuan, Y. Wang, Applied Energy, 2019, 236, 70-80, doi: 10.1016/j.apenergy.2018.11.091.

[162] M. M. Umair, Y. Zhang, A. Tehrim, S. Zhang, B. Tang, Industrial \& Engineering Chemistry Research, 2020, 59, 1393 1401, doi: 10.1021/acs.iecr.9b06288.

[163] R. Hergt, S. Dutz, M. Zeisberger, Nanotechnology, 2010, 21, 015706, doi: 10.1088/0957-4484/21/1/015706.

[164] J.-P. Fortin, F. Gazeau, C. Wilhelm, European Biophysics Journal, 2008, 37, 223-228, doi: 10.1007/s00249-007-0197-4.

[165] Y. Dai, J. Su, K. Wu, W. Ma, B. Wang, M. Li, P. Sun, Q. Shen, Q. Wang, Q. Fan, ACS Applied Materials \& Interfaces, 2019, 11, 10540-10553, doi: 10.1021/acsami.8b22748.

[166] Q. Zhang, Z. He, X. Fang, X. Zhang, Z. Zhang, therapy Energy Storage Materials, 2017, 6, 36-45, doi: 10.1016/j.ensm.2016.09.006.

[167] F. Jiang, X. Wang, D. Wu, Energy, 2016, 98, 225-239, doi: 10.1016/j.energy.2016.01.008.

[168] X. Zhuang, Y. Zhang, C. Cai, Scientific reports, 2018, 8, 16479, doi: 10.1038/s41598-018-34583-5.

[169] J. Li, Y. Hu, Y. Hou, X. Shen, G. Xu, L. Dai, J. Zhou, Y. Liu, K. Cai, Nanoscale, 2015, 7, 9004-9012, doi: 10.1039/c5nr01744k. [170] W. Wang, B. Tang, B. Ju, Z. Gao, J. Xiu, S. Zhang, Journal of Materials Chemistry A, 2017, 5, 958-968, doi: 10.1039/c6ta07144a.

[171] X. Fan, J. Xiao, W. Wang, Y. Zhang, S. Zhang, B. Tang, Polymers, 2018, 10, 585, doi: 10.3390/polym10060585.

[172] W. Wang, X. Fan, J. Qiu, M. M. Umair, B. Ju, S. Zhang, B. Tang, Chemical Engineering Journal, 2019, 358, 1279-1286, doi: 10.1016/j.cej.2018.10.118.

[173] R. Ghosh, L. Pradhan, Y. P. Devi, S. S. Meena, R. Tewari, A. Kumar, S. Sharma, N. S. Gajbhiye, R. K. Vatsa, B. N. Pandey, 
R. S. Ningthoujam, Journal of Materials Chemistry, 2011, 21, 13388, doi: 10.1039/c1jm10092k.

\section{Author information}

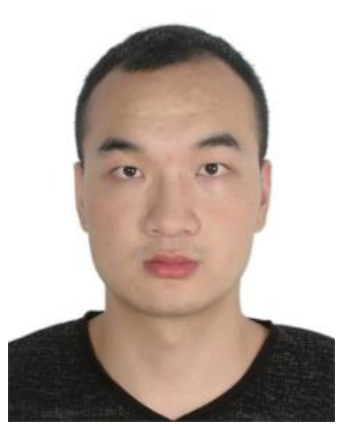

Ximpeng $\mathrm{Hu}$ is currently a Ph.D. Candidate under the supervision of Prof. Jinping Qu and associate Prof. Xiang Lu in the School of Chemistry and Chemical Engineering, Huazhong University of Science and Technology. He received his master's degree from Harbin Institute of Technology and bachelor's degree from Tianjin University. His research interests mainly focus on the functional composites for green energy utilization.

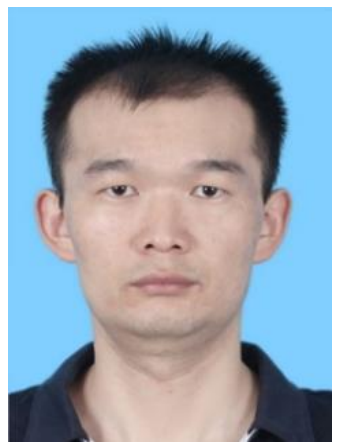

Hao $\boldsymbol{W u}$ is currently doing postdoctoral research in Prof. Jinping Qu's group in the School of Chemistry and Chemical Engineering, Huazhong University of Science and Technology. He received his doctor's degree from South China University of Technology and his master's and bachelor's degrees from Qingdao University of Science and Technology. His research interests mainly focus on the new theory and equipment of polymer material processing and preparation of functional composites.

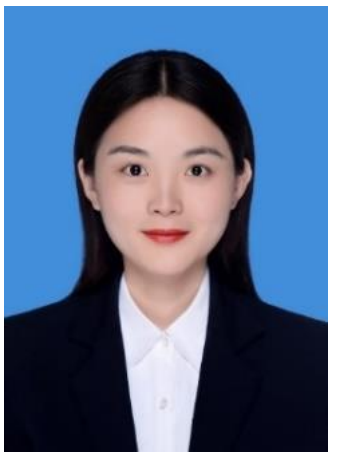

Shuang Liu is currently working in academician Jinping Qu's group as a Ph.D. candidate in the Key Laboratory of Material Chemistry for Energy Conversion and Storage of Ministry of Education, School of Chemistry and Chemical Engineering, Huazhong University of Science and Technology. She received her Master degree from the State Key Laboratory of Inorganic Synthesis and Preparative Chemistry, College of Chemistry, Jilin University in 2019. Her research interests mainly focus on the synthesis and applications of functional phase change materials with green, renewable and environmental protection in energy storage.

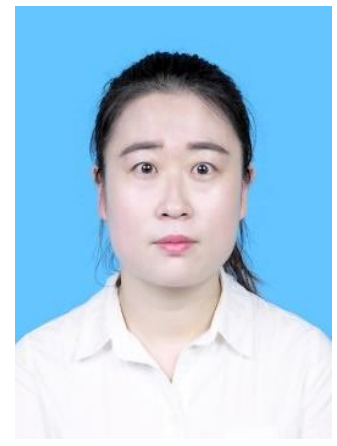

Shang Gong currently works as a Ph.D. candidate in the School of Chemistry and Chemical Engineering, Huazhong University of Science and Technology. She obtained her master degree from Guizhou University. Her main research interest is the development of phase change materials with high thermal

conductivity for waste heat recovery.

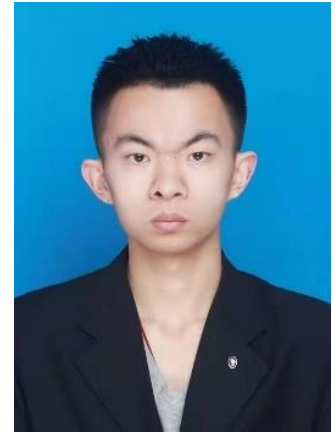

$\mathbf{Y u} \mathbf{D u}$ is currently a Ph.D. candidate in school of Chemistry and Chemical Engineering, Huazhong University of science and technology. His main research interest is processing and modification of polymer functional composites. He obtained master's degree of mechanical engineering from Beijing University of Chemical Technology in 2020. He hopes to use his knowledge to solve difficult problems in these field.

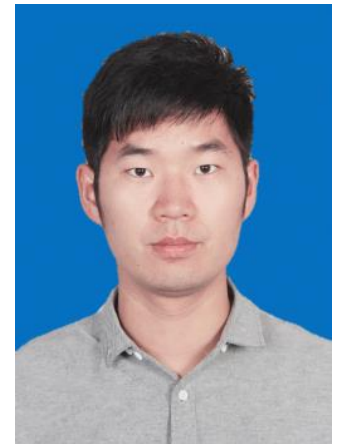

Xiaolong Li is currently a Ph.D. candidate in the group of Academician Qu Jinping, School of Chemistry and Chemical Engineering, Huazhong University of Science and Technology. He obtained the master degree from the College of Materials and Metallurgy of Guizhou University. His main research areas are functional phase change materials for energy storage, and modification of biodegradable materials.

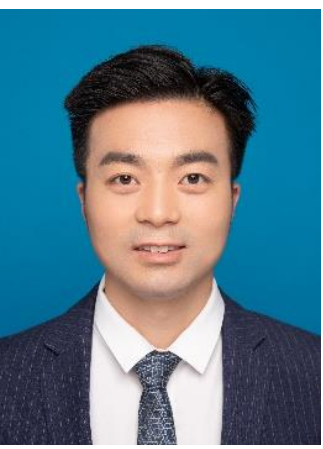

Xiang $\mathbf{L u}$ is currently an associate professor and Ph.D. supervisor in the Key Laboratory of Material Chemistry for Energy Conversion and Storage of Ministry of Education, School of Chemistry and Chemical Engineering at Huazhong University of Science and Technology, China. He received his Ph.D. from South China University of Technology. His research interests mainly focus on the design and fabrication of multi-functional materials especially for efficient energy utilization. 


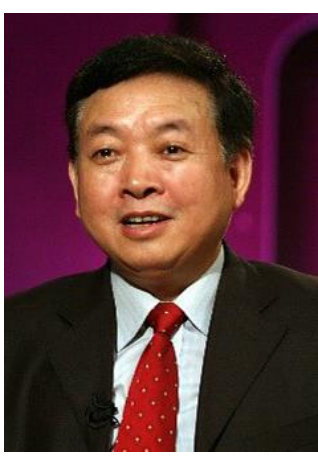

Qu Jinping is currently a professor in School of Chemistry and Chemical Engineering at Huazhong University of Science and Technology, and the academician of the Chinese Academy of Engineering. He received his Ph.D. from Sichuan University. His research interests mainly focus on design and fabrication of polymer processing equipment as well as the corresponding theory.

Publisher's Note: Engineered Science Publisher remains neutral with regard to jurisdictional claims in published maps and institutional affiliations. 